\title{
Changes in reward-related signals in the rat nucleus accumbens measured by in vivo oxygen amperometry are consistent with fMRI BOLD responses in man
}

\author{
Jennifer Francois ${ }^{\text {a,* }}$, Michael W. Conway ${ }^{\text {a }}$, John P. Lowry ${ }^{\mathrm{b}}$, Mark D. Tricklebank ${ }^{\mathrm{a}}$, Gary Gilmour ${ }^{\mathrm{a}}$ \\ a Lilly Centre for Cognitive Neuroscience, Lilly Research Laboratories, Eli Lilly \& Co. Ltd, Erl Wood Manor, Windlesham, Surrey, UK \\ ${ }^{\mathrm{b}}$ Department of Chemistry, National University of Ireland Maynooth, Co. Kildare, Ireland
}

\section{A R T I C L E I N F O}

\section{Article history:}

Accepted 8 February 2012

Available online 21 February 2012

\section{Keywords:}

Oxygen amperometry

Nucleus accumbens

Reward

Anticipation

fMRI

\begin{abstract}
A B S T R A C T
Real-time in vivo oxygen amperometry, a technique that allows measurement of regional brain tissue oxygen $\left(\mathrm{O}_{2}\right)$ has been previously shown to bear relationship to the BOLD signal measured with functional magnetic resonance imaging (fMRI) protocols. In the present study, $\mathrm{O}_{2}$ amperometry was applied to the study of reward processing in the rat nucleus accumbens to validate the technique with a behavioural process known to cause robust signals in human neuroimaging studies. After acquisition of a cued-lever pressing task a robust increase in $\mathrm{O}_{2}$ tissue levels was observed in the nucleus accumbens specifically following a correct lever press to the rewarded cue. This $\mathrm{O}_{2}$ signal was modulated by cue reversal but not lever reversal, by differences in reward magnitudes and by the motivational state of the animal consistent with previous reports of the role of the nucleus accumbens in both the anticipation and representation of reward value. Moreover, this modulation by reward value was related more to the expected incentive value rather than the hedonic value of reward, also consistent with previous reports of accumbens coding of "wanting" of reward. Altogether, these results show striking similarities to those obtained in human fMRI studies suggesting the use of oxygen amperometry as a valid surrogate for fMRI in animals performing cognitive tasks, and a powerful approach to bridge between different techniques of measurement of brain function.

(c) 2012 Elsevier Inc. All rights reserved.
\end{abstract}

\section{Introduction}

Translational validity, the ability of animal research to inform or predict effects in humans, remains a critical imperative of modern neuroscience. In pursuit of the relationships between neuronal function and behaviour, techniques such as functional magnetic resonance imaging (fMRI) essentially revolutionized human cognitive neuroscience by providing a means to indirectly assess brain activation in subjects performing neuropsychological tasks. At present, the scope of imaging work in rodents is largely limited to nonbehavioural studies as animals have to remain motionless during scanning. However, real-time in vivo oxygen amperometry may help to bridge the gap here. This technique allows measurement of regional brain tissue oxygen $\left(\mathrm{O}_{2}\right)$ levels in freely moving animals and it has been previously shown that such signals closely relate to BOLD signals when measured simultaneously (Lowry et al., 2010). Other work has shown that in vivo $\mathrm{O}_{2}$ amperometric signals also seem to be closely related to neuronal activity measures of synaptic and local field activity (Masamoto et al., 2008; Thompson et al., 2003; Viswanathan and Freeman, 2007). Thus, oxygen amperometry may

\footnotetext{
* Corresponding author at: Lilly Centre for Cognitive Neuroscience, Eli Lilly \& Co. Ltd, Erl Wood Manor, Sunninghill Road, Windlesham, Surrey, GU20 6PH, UK. Fax: + 44 1256483525.

E-mail address: francoisje@lilly.com (J. Francois).
}

represent a measurement of brain activity that is practically positioned between classical in vivo electrophysiological measures in animals and fMRI in humans, providing a translational bridge between the two.

Reward processing plays a critical role in basic cognitive functions and reward pathways are highly conserved across species (Ongur and Price, 2000), making this aspect of brain function a practical yet attractive target for the validation of approaches to translational research. Many studies have identified a distributed mesolimbic network that can be characterized as a "reward pathway" in the brain. A neuronal projection known to be fundamental for processing reward-related signals involves dopaminergic innervations of the nucleus accumbens core and shell from the ventral tegmental area (VTA) (Dahlström and Fuxe, 1964; Fallon and Moore, 1978; Swanson, 1982). Electrophysiological work in rodents and nonhuman primates have linked response to positive outcome or the conditioned stimuli that predict these outcomes to activation of midbrain dopamine neurons projecting to the nucleus accumbens (NAc) (Nicola et al., 2004; Olds and Milner, 1954; Schultz et al., 1997; Tobler et al., 2005). VTA activity has now been heavily implicated in the performance of much reward-related behaviour (e.g. see review by Fields et al., 2007). By virtue of its extensive efferent connectivity from the VTA, the NAc is also key to the processing of reward-related signals. For instance, human imaging studies have shown a consistent activation of the NAc to the presence of many different types of reward such 
as monetary gain (Knutson et al., 2001), pleasant taste (O'Doherty, 2004) and smiling faces (Spreckelmeyer et al., 2009). In general, neuroimaging studies suggest that many aspects of the findings related to reward pathway function and activity in animals also generalise to humans (Knutson and Cooper, 2005).

In the present work, in vivo oxygen amperometry has been applied to the study of reward processing in the nucleus accumbens (NAc) to validate the technique with a behavioural process known to cause robust BOLD signals in human fMRI studies. In vivo $\mathrm{O}_{2}$ amperometric recordings were carried out in animals performing a cued-lever pressing task for food reward. These animals underwent several behavioural manipulations in order to dissociate different aspects of reward, including reversals of lever and cue contingencies, modulations of reward value and modulations of motivational state. Previous assessments of accumbens function, for example with in vivo electrophysiology, dopamine voltammetry or imaging techniques, during manipulations of reward-related behaviour offered a benchmark against which our results could be compared.

\section{Material and methods}

\section{Animals}

Adult male Sprague Dawley rats (Charles River, UK) were used in the present studies (Experiment 1: $n=16$; Experiment 2: $n=16$ ). Prior to surgery, animals (250-300 g) were housed in standard housing conditions (four per cage, 07:00 h to 19:00 h light phase, controlled temperature and humidity, ad libitum water). After surgery, they were singly-housed in the same environment. All animals were kept for a period of 7 days before any behavioural procedure started. During this time, rats were acclimated to the food restriction regime (i.e., maintained at no less than $85 \%$ of their free-feeding weight) and were handled regularly. All experiments were conducted in accordance with the United Kingdom Animals Scientific Procedures Act 1986.

\section{Electrode construction}

Carbon paste electrodes (CPEs) were constructed from 8T (200 $\mu \mathrm{m}$ bare diameter, $270 \mu \mathrm{m}$ coated diameter) Teflon ${ }^{\circledR}$-coated silver wire (Advent Research Materials, Suffolk, UK) as described previously (McHugh et al., 2011). The Teflon insulation was slid along the wire to create an approximately 2-mm deep cavity, which was packed with carbon paste. Carbon paste was prepared by thoroughly mixing $7.1 \mathrm{~g}$ of carbon graphite powder and $2.5 \mathrm{ml}$ of silicone oil (both from Sigma-Aldrich, UK) (O'Neill et al., 1982). Reference and auxiliary electrodes were also prepared from $8 \mathrm{~T}$ Teflon ${ }^{\circledR}$-coated silver wire by removing the Teflon from the tip. All electrodes were soldered to gold connectors, which were cemented into six-pin plastic sockets (both from Plastic One, Roanoke, VA) during surgery.

\section{Electrode calibration}

Prior to implantation, all CPEs were calibrated in vitro in a standard three-electrode glass electrochemical cell (BASi C3 cell stand, Bioanalytical Systems, USA) with an $\mathrm{Ag} / \mathrm{AgCl}$ reference electrode, and a BASi platinum auxiliary electrode. Calibrations were performed in a $15 \mathrm{ml}$ phosphate buffer saline solution, pH 7.4 saturated with nitrogen $\left(\mathrm{N}_{2}\right)$ gas, atmospheric air (from a RENA air pump), or pure $\mathrm{O}_{2}$ at room temperature providing a three-point calibration of known concentrations of $0 \mu \mathrm{M}$ ( $\mathrm{N}_{2}$-saturated), $240 \mu \mathrm{M}$ (air-saturated) and $1260 \mu \mathrm{M}\left(\mathrm{O}_{2}\right.$-saturated) oxygen. CPEs were chosen for implantation if their calibration curves were linear and the measured oxygen values from the saturated solutions were not greatly different from those expected (least square linear regression, $\mathrm{R}^{2} \geq 0.98$ ).

\section{Surgery}

Animals were placed in vaporization chambers and anaesthetised with $5 \%$ isofluorane $\left(2 \mathrm{~L} / \mathrm{min}_{2}\right)$ and maintained on $1-3 \%$ isofluorane $\left(2 \mathrm{~L} / \mathrm{min}_{2}\right)$ for the rest of the procedure. CPEs were implanted in the NAc (from bregma: AP $+1.9 \mathrm{~mm}, \mathrm{ML} \pm 0.8 \mathrm{~mm}, \mathrm{DV}:-6.9 \mathrm{~mm}$ ). The reference electrode was inserted into the posterior cortex to a depth of $2 \mathrm{~mm}$ and secured with cement. The auxiliary electrode was wrapped round a skull screw positioned over posterior cortex. After all electrodes were cemented into place, the gold sockets of the electrodes were inserted into a six-pin plastic socket. All animals were administered Rimadyl (Carprofen $5 \mathrm{mg} / \mathrm{kg}$ s.c.) both pre and post surgically and were allowed to recover in thermostatically controlled cages.

\section{Amperometric techniques}

Changes in extracellular tissue oxygen concentration were measured using constant potential amperometry (CPA) at CPEs as described previously (Lowry et al., 1997). Briefly, a negative potential $(-650 \mathrm{mV})$ was applied to the CPE to allow the electrochemical reduction of dissolved oxygen to occur at the tip of the electrode. This potential is in the mass-transport limited region after the peak potential for $\mathrm{O}_{2}$ reduction $(\mathrm{ca} .-500 \mathrm{mV}$ ) and has previously been shown to be appropriate for $\mathrm{CPA} \mathrm{O}_{2}$ detection using cyclic voltammetry (Lowry et al., 1996). Electrochemical reduction of $\mathrm{O}_{2}$ at carbon electrodes is a two-electron process producing $\mathrm{H}_{2} \mathrm{O}_{2}$ :

$\mathrm{O}_{2}+2 \mathrm{H}^{+}+2 \mathrm{e}^{-} \rightarrow \mathrm{H}_{2} \mathrm{O}_{2}$

$\mathrm{H}_{2} \mathrm{O}_{2}+2 \mathrm{H}^{+}+2 \mathrm{e}^{-} \rightarrow 2 \mathrm{H}_{2} \mathrm{O}$

Since the direct reduction (Martel and Kuhn, 2000) and oxidation (Zimmerman and Wightman, 1991) of $\mathrm{H}_{2} \mathrm{O}_{2}$ is severely inhibited at carbon electrode surfaces the rate-limiting step is the initial oneelectron transfer followed by protonation of the superoxide ion and further reduction (Taylor and Humffray, 1975). Therefore, changes in the measured current that are produced by the electrochemical reduction of $\mathrm{O}_{2}$ are directly proportional to the local extracellular tissue $\mathrm{O}_{2}$ concentration (Hitchman, 1978). Moreover, since the dimension of CPEs (typically $100-200 \mu \mathrm{m}$ ) (Justice, 1987) is greater than the scale of a capillary zone $(<100 \mu \mathrm{m})$, an average extracellular tissue $\mathrm{O}_{2}$ level is detected regardless of the orientation of the electrode relative to the blood vessels and metabolically active sites, or the depth of penetration into the tissue.

\section{In vivo signal validation}

To demonstrate the oxygen sensitivity of the electrodes in vivo, mild hyperoxia and hypoxia was induced by applying gaseous $\mathrm{O}_{2}$ (BOC medical, Manchester, UK) or $\mathrm{N}_{2}$ (BOC gases, Guildford, UK), respectively, to the snout of the animal before and after each experiment. Polyurethane tubing, connected to the appropriate gas cylinder, was held approximately $2 \mathrm{~cm}$ from the snout and the gas delivered for either $60 \mathrm{~s}\left(\mathrm{O}_{2}\right)$ or $30 \mathrm{~s}\left(\mathrm{~N}_{2}\right)$ at a flow rate of $1 \mathrm{~L} / \mathrm{min}$.

\section{Oxygen amperometry data recording}

Rats were connected to a four channel potentiostat (Biostat, ACM Instruments, Cumbria, UK) through a 6-pin socket (Plastics One, Roanoke, VA, USA) and a flexible screened 6-core cable (Plastics One). A PowerLab 8/30 was used for analogue/digital conversion and data were collected on a PC running Chart_v5 software (AD Instruments, Oxford, UK). The $\mathrm{O}_{2}$ signal was recorded at a sample rate of $200 \mathrm{~Hz}$. For all test sessions where an oxygen amperometric signal was 
recorded, animals were tethered and a constant potential ( $-650 \mathrm{mV})$ was applied for the duration of the session.

\section{Oxygen amperometry data analysis}

All post-acquisition signal analysis was conducted with MATLAB 2009 software. Since different CPEs can have different levels of sensitivity to $\mathrm{O}_{2}$, it is not generally meaningful to directly compare signals from different CPEs to each other. Thus, $\mathrm{O}_{2}$ signals recorded from each CPE were normalized according to their baseline (i.e., current averaged over a $1 \mathrm{~s}$ period before the beginning of the trial) using the following formula: Oxygen level changes $(n A)=$ (Current $(n A)-$ Average Baseline $(\mathrm{nA})) \mathrm{X} *-1$. After normalization, a $40 \mathrm{~s}$ window of data ( $10 \mathrm{~s}$ before and $30 \mathrm{~s}$ after cue onset) related to each behavioural response (see $\mathrm{O}_{2}$ amperometry recordings in the nucleus accumbens in response to rewarded and non-rewarded cues (Experiment 1) section) was subjected to a session averaging process. Active (rewarded) and inactive (non-rewarded) lever presses for the $\mathrm{S}+$ cues (those predicting reward) and any lever press for the $S$ - cues (those predicting no reward) were analysed separately and averaged over the session for each animal. These averaged signals were then reduced to $0.5 \mathrm{~s}$ time bins, and the $\mathrm{O}_{2}$ responses were compared using repeated-measures analysis of variance (ANOVA) followed by Fisher's LSD test for post-hoc analysis. Moreover, the area under the curve (AUC) and the maximum amplitude (peak) of the signal were extracted from the average curve obtained for each behavioural outcome. Before each analysis, the area and peak were plotted in 2D to identify potentially extreme non-physiological values for exclusion from analysis. General linear model factorial ANOVA was used for analysis followed by LSD Fisher's test. As CPEs are implanted bilaterally, a main effect of Side was also assessed in a preliminary analysis. However, as no effect of Side was observed during any part of the study, signals from both hemispheres of the brain of each subject were averaged. All statistics were conducted using Statistica (v9) software.

\section{Behavioural experiments}

\section{Apparatus}

Standard operant chambers housed in sound and light attenuating chambers were used (Med-associates, Vermont, USA). Each chamber contained a house light (100 mA, Med-Associates; ENV $215 \mathrm{M}$ ) and two retractable levers. The levers were located on either side of a recessed magazine where food pellets (Noyes, $45 \mathrm{mg}$, Formula P) were delivered from an automatic pellet dispenser. Auditory signals using a continuous tone $(70 \mathrm{~dB}, 4000 \mathrm{kHz})$ and a clicker were produced by a tone generator located on the opposite wall to the food magazine. Experimental sessions were controlled and data recorded using in-house programmes written with MedPC-IV software (MedAssociates, Vermont, USA) and data prepared for analysis using an in-house excel macro designed for each experiment.

\section{$\mathrm{O}_{2}$ amperometry recordings in the nucleus accumbens in response to} rewarded and non-rewarded cues (Experiment 1)

In Experiment 1, prior to surgery, rats were trained to discriminate between two auditory cues (S1 and S2) to receive food reward: a discriminative stimulus $(\mathrm{S} 1+)$ which predicted the delivery of reward after an operant response (lever press) with $100 \%$ probability, and a non-rewarded stimulus (S2-) that had no response contingency or consequence. Auditory cues (tone or clicker) and rewarded lever position (left or right) were counterbalanced across the squad of animals. S1+ and S2- cues were presented pseudorandomly in no greater than trains of two.

During all training steps, the session start was signalled by houselight onset, and its permanent offset indicated the end of a session. Training proceeded according to the following steps (adapted from Nicola et al., 2005). (1) All animals were given a 30 min session to familiarize themselves with the recessed food magazine. Pellets were delivered on a variable interval (VI) 60 second schedule and head entries were recorded. (2) The next day, animals were trained to lever press for food pellets ( $45 \mathrm{~min}$ ) on a concurrent VI15-VI15 schedule. After 100 pellets were earned, cue association training began. (3) From this point forwards, a $30 \mathrm{~min}$ habituation period was added before the test session start to accommodate stabilisation of the amperometric signal following application of the potential. S1+ and S2 - stimuli were presented during the test session for up to $60 \mathrm{~s}$, where extension of the levers was coincident with stimulus onset. Pressing an active lever for S1 + terminated the cue, retracted both levers and delivered a reward. Pressing for S2 - also terminated the cue and retracted both levers, but did not deliver reward. These sessions continued for 4 days. (4) Stimuli presentation time was subsequently reduced to $10 \mathrm{~s}$, again with lever extension coincident with stimulus onset. Animals progressed to the final stage of training when they reached a criterion of greater than $75 \%$ of the $S 1+$ trials resulting in choice of the active lever while presentation of S2 - resulted in mainly omissions (5) During the final stage of training, stimuli presentation time was maintained at $10 \mathrm{~s}$ but the levers were only presented at cue offset. An active lever press after S1+ retracted both levers and delivered one pellet of food as reward. This was followed by a 20 s interval (houselight on) before the next trial started. An inactive lever press or omission was followed by a $20 \mathrm{~s}$ timeout (houselight off) before the next trial began. Levers were available for $5 \mathrm{~s}$ before they retracted and an omission was recorded if neither was pressed in that time. As for $\mathrm{S} 1+$ presentation, both levers were also presented immediately following the S2 - stimulus. In this case, active or inactive lever presses, or withholding responding had no consequence. Following an S2presentation, there was a $20 \mathrm{~s}$ interval before the next trial. Animals were considered fully trained and ready for surgery when they reached a criterion of greater than $75 \%$ active lever presses for $\mathrm{S} 1+$ while presentation of S2- resulted mainly in omissions for three consecutive days. At this point the amperometric electrodes were implanted as described above (see Surgery section).

Two weeks after surgery, animals were retrained on the behavioural task. Oxygen amperometric recordings took place from the first day of retraining and during a series of reversals of the cue and lever contingencies in the following order: lever reversal 1, cue reversal 1, lever reversal 2, and cue reversal 2. For each step of the study, behavioural performance and $\mathrm{O}_{2}$ amperometric signals were recorded on the first day of reversal and also after the new discrimination was fully re-learned. Behavioural performances were assessed by measuring the number of active (rewarded) and inactive (non-rewarded) lever presses and the number of omissions for each stimulus. The response ratio (proportion of stimuli to which the animal responded by a lever press) and the accuracy (proportion of active lever presses following $\mathrm{S}+$ stimuli) were also measured.

\section{$\mathrm{O}_{2}$ amperometry recordings in the nucleus accumbens in response to differences in reward magnitude (Experiment 2)}

In order to assess the effect of magnitude of reward on behavioural performance and $\mathrm{O}_{2}$ amperometric signals in the NAc, a modified version of the rewarded cue discrimination task was employed (Experiment 2). Three auditory cues (a continuous tone, an intermittent tone and a clicker) were presented to provide a $\mathrm{S} 1+$ low (lever $1-$ low reward: 1 pellet), $\mathrm{S} 2+_{\text {high }}$ (lever 2 -high reward: 3 pellets) and S3- (lever press, no reward). As for the basic version of the task, cues and lever positions were counterbalanced across the squad of animals. The training procedure was effectively the same as described for Experiment 1, except that three rather than two cues were presented to animals at the appropriate training stages. Animals were not required to meet performance criteria relating to the S3-, but had to exhibit greater than $75 \%$ accuracy for both $\mathrm{S} 1+_{\text {low }}$ and $\mathrm{S} 2+_{\text {high }}$ for three consecutive days before surgery for the implantation of amperometric electrodes (see Surgery section). 

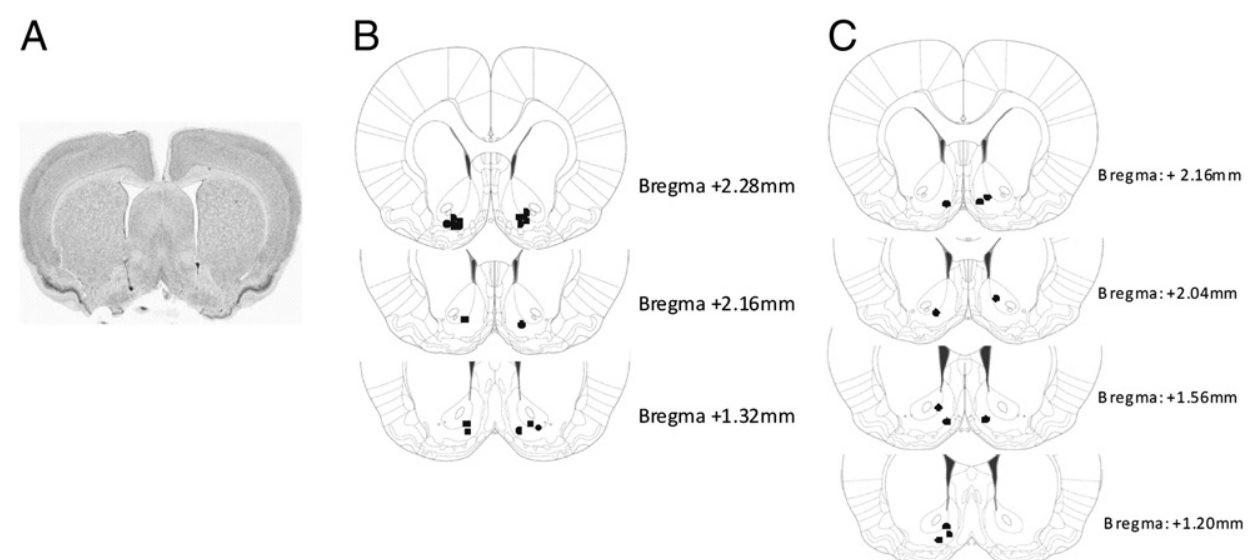

Fig. 1. Photomicrographs (A) and reconstructions of electrode placements in the nucleus accumbens for Experiments 1 (B) and 2 (C).Coronal sections for the reconstructions are taken from the atlas of Paxinos and Watson (2005), plates 14, 15, and 22 for Experiment 1 (B) and from plates 15, 16, 20 and 22 for Experiment 2 (C). The tip of each CPE is represented by a black circle.

Two weeks after surgery, animals were retrained on the behavioural task until they reached the presurgical performance criterion. Tissue oxygen levels were recorded (as described previously) when the animals were (1) fully trained to task, (2) directly after a prefeeding to satiety procedure, where rats were given access to food ad libitum during the night before the test day, and (3) after reversal of the $\mathrm{S} 1$ and S2 reward contingencies. For this reversal, tissue $\mathrm{O}_{2}$ levels were recorded on the days immediately before and after the manipulation, at a mid-point where task acquisition was partial and again when the discrimination was fully re-learned. Behavioural performances were recorded at the same time-point by measuring the number of active and inactive lever presses, the number of omissions and the response ratio (proportion of stimuli responded to by a lever press), and the accuracy for both the $\mathrm{S} 1+_{\text {low }}$ and $\mathrm{S} 2+_{\text {high }}$ cues (proportion of active lever presses following each $\mathrm{S}+$ stimuli).

\section{Histology}

In order to check the placement of CPEs at the end of experimentation, animals were deeply anesthetized with pentobarbital and perfused transcardiacally with $0.9 \%$ saline followed by $10 \%$ buffered paraformaldehyde. Brains were removed and placed in 10\% buffered paraformaldehyde solution and shipped for histological processing (Neuroscience Associates Inc., Knoxville, TN, U.S.A.), which involved coronal sectioning $(40 \mu \mathrm{m})$ through relevant brain areas using MultiBrain ${ }^{\circledR}$ Technology (Neuroscience Associates Inc.) and staining with thionin for Nissl substance. Slides were viewed microscopically to assess placement of electrode tips and signals obtained from any CPE with improper placement were excluded from all analyses.

\section{Results}

Experiment 1: $\mathrm{O}_{2}$ amperometry recordings in the nucleus accumbens in response to rewarded and non-rewarded cues

\section{Histology}

Following exclusion of unstable or noisy signals, 8 animals had correct bilateral placements in the NAc that could be recorded from during the entire study. All graphs presented in this section represent the average responses of only those rats. Reconstructions and a representative photomicrograph from one rat are shown in Fig. 1A and B.

\section{$\mathrm{O}_{2}$ Amperometry recordings in the NAc after task acquisition (Fig. 2)}

Once the rewarded cue discrimination task was acquired, animals pressed the active lever following the S1+ cue for the majority of S1+ trials (91.8 $\pm 2.8 \%$ accuracy) and so received reward, and omitted responding to the $\mathrm{S} 2-$ cue on $72.3 \pm 7.8 \%$ of the $\mathrm{S} 2-$ trials
(Fig. 2A). At this stage of performance, an increase in the $\mathrm{O}_{2}$ signal was only observed for active lever presses following $\mathrm{S} 1+$, while no significant changes could be observed for inactive lever presses
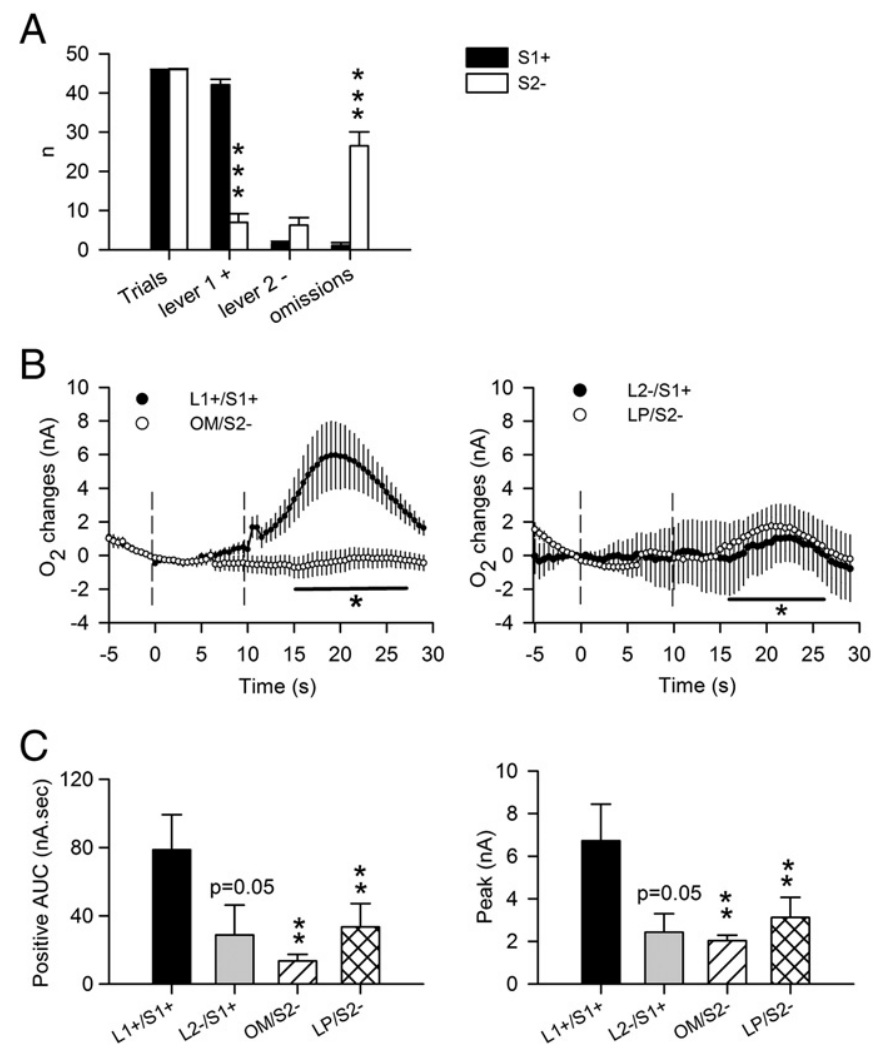

Fig. 2. Behavioural performance (A) and $\mathrm{O}_{2}$ amperometric responses recorded in the nucleus accumbens $(B, C)$ after the acquisition of a rewarded cue task (Experiment 1 ). All results are presented as mean \pm standard error of the mean. (A) The total number of trials, rewarded lever presses (lever $1+$ ), non-rewarded lever presses (lever 2-) and omissions are presented for the rewarded stimulus ( $\mathrm{S} 1+$, black bars) and the non-rewarded stimulus (S2-, white bars). ${ }^{* * *} \mathrm{p}<0.0001$ compared to $\mathrm{S} 1+$. (B) Left graph: averaged $\mathrm{O}_{2}$ amperometric responses for "correct" responses, i.e. active lever press following the rewarded cue $(\mathrm{L} 1+/ \mathrm{S} 1+)$ and omission following non-rewarded cue (OM/S2-). Right graph: averaged $\mathrm{O}_{2}$ amperometric responses for "incorrect" responses, i.e. inactive lever press or omission following the rewarded cue (L2-/S1+) and any lever press following the non-rewarded cue (LP/S2-). Dashed lines represent the beginning and end of cue presentations. *: $\mathrm{p}<0.01$ compared to $\mathrm{O}_{2}$ response obtained for $\mathrm{L} 1+/ \mathrm{S} 1+$. (C) Area under the curve (AUC, left) and Peak (right) measurements extracted from $\mathrm{O}_{2}$ responses obtained for correct or incorrect responses the rewarded cue $(\mathrm{L} 1+/ \mathrm{S} 1+$ and $\mathrm{L} 2-/ \mathrm{S} 1+$ respectively) and omissions or lever presses for the non-rewarded cue $(\mathrm{OM} / \mathrm{S} 2-$ and $\mathrm{LP} / \mathrm{S} 2$ - respectively). ${ }^{* *} \mathrm{p}<0.01$ compared to 02 response obtained for $\mathrm{L} 1+/ \mathrm{S} 1+$. 
following $\mathrm{S} 1+$ and omissions or any lever presses following S2(Fig. 2B). Analysis of time-binned tissue $\mathrm{O}_{2}$ data revealed a significant interaction between behavioural response and time $\left(\mathrm{F}_{204,1836}=2.83\right.$, $\mathrm{p}<0.001$ ), with a trend towards a main effect of behavioural response $\left(F_{3,27}=2.79, p=0.059\right)$. These results were confirmed by analysis of AUC and Peak measures, which showed a significant main effect of behavioural response for Peak $\left(F_{3,24}=3.6, p=0.02\right)$ and AUC values $\left(F_{3,24}=3.7, p=0.02\right)$. Post-hoc comparisons demonstrated that these effects were driven by greater peak and AUC values obtained for a rewarded lever press following $\mathrm{S} 1+$ cue presentation relative to signals produced by all other behavioural responses (Fig. 2C).

\section{$\mathrm{O}_{2}$ Amperometry recordings in the NAc after lever reversal (Fig. 3)}

A lever reversal procedure was administered so that $\mathrm{S} 1+$ cues would now only result in reward by pressing lever 2 (previous inactive lever), while pressing lever 1 (previous active lever) had no outcome. The nature of both $\mathrm{S} 1+$ and $\mathrm{S} 2-$ cues remained unchanged. Behavioural responses and tissue $\mathrm{O}_{2}$ levels were analysed at three time points: the day before lever contingencies were reversed, the first day after levers were reversed and when the new rule was fully learned with animals reaching a stable level of performance for three consecutive days.

Compared to the day before lever reversal, behavioural responses of animals did not immediately change during the first day of reversal: following S1+ cues, animals still pressed lever 1 , the previously active lever (Fig. 3, REV DAY1). Lever reversal also had no immediate effect on behavioural responses following S2 - cues. However, after a period of training on the lever reversal protocol, animals pressed the new active lever following $S 1+$ cues $(92.6 \pm 1.3 \%$ of $S 1+$ trials), as shown in Fig. 3 ("FT" row). Again, omissions and behavioural responses to S2- cues remained unchanged. Analysis of timebinned tissue $\mathrm{O}_{2}$ data during the different stages of lever reversal (repeated measure ANOVA: behavioural response $\times$ time $\times$ day) revealed a significant effect of behavioural response $\left(F_{3,76}=5.3, p<0.01\right)$, but no effect of day $\left(F_{2,76}=0.17, p=0.83\right)$ or of the triple interaction $\left(F_{408,5168}=0.86, p=0.97\right)$. Thus, despite the fact that there was a significant change in behavioural response induced by lever reversal (i.e. a switch from the previous active lever to the new active lever following $\mathrm{S} 1+$ cues), $\mathrm{O}_{2}$ signals corresponding to $\mathrm{S} 1+$ cues were not significantly affected (Fig. 3, middle column). These results were confirmed by analysis of extracted AUC and Peak measurements (ANOVA: behavioural outcome $\times$ day) showing a significant effect of behavioural response for Peak $\left(\mathrm{F}_{3,136}=7.57, \mathrm{p}<0.001\right)$ and AUC values $\left(\mathrm{F}_{3,136}=12.82, \mathrm{p}<0.001\right)$ but no significant behavioural response $\times$ day interaction $\left(\mathrm{F}_{12,246}=0.27, \mathrm{p}=0.99\right)$. This effect was driven by greater Peak and AUC values obtained for rewarded lever presses following $\mathrm{S} 1+$ cue presentations (Fig. 3, right column).

\section{$\mathrm{O}_{2}$ Amperometry recordings in the NAc after cue reversal (Fig. 4)}

A cue reversal procedure was administered, where $\mathrm{S} 1+$ and $\mathrm{S} 2-$ cue contingencies were reversed so that $\mathrm{S} 2$ now predicted reward with $100 \%$ probability $(S 2+)$ and $S 1$ (previous $S+$ cue) now had no consequence $(\mathrm{S} 1-)$. Lever contingencies remained constant during this procedure.

Cue reversal had an immediate effect on the behavioural response to S2 cues (previously $\mathrm{S}-$ now $\mathrm{S}+$ ). On day 1 of cue reversal, animals pressed the active lever for S2 on $72.6 \pm 10.5 \%$ of $S 2+$ cued trials compared to only $25.9 \pm 7.1 \%$ of S1 - trials with relatively few omissions $(7.7 \pm 3.9 \%$ omission rate, compared to $66.7 \pm 7.9 \%$ omission rate on the previous day when acquisition of the task had reached
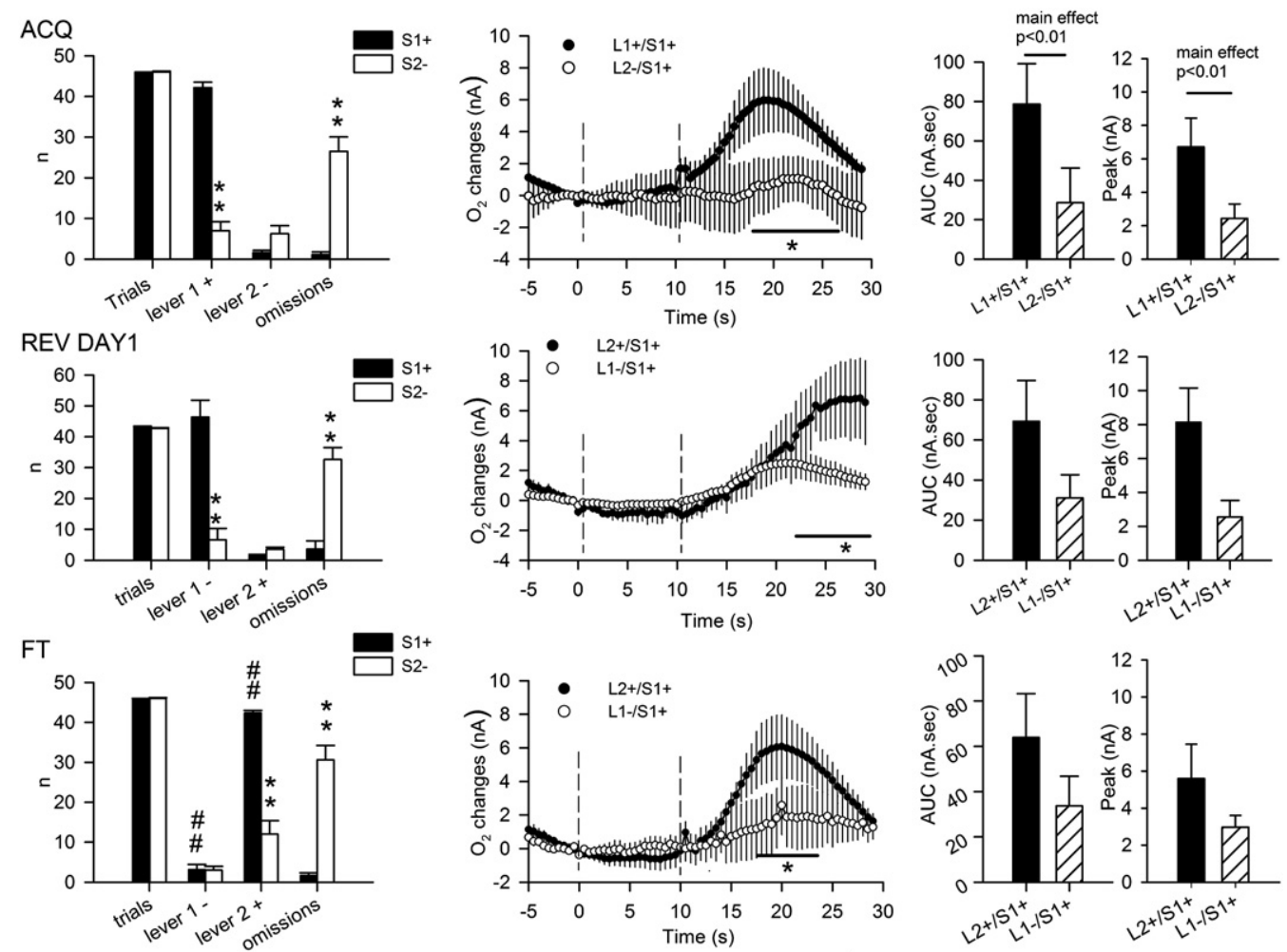

Fig. 3. Behavioural performance and $\mathrm{O}_{2}$ amperometric responses recorded in the nucleus accumbens during a lever reversal procedure (Experiment 1 ). All results are presented as mean \pm standard error of the mean. Top row: Acquired (ACQ) task performance; Middle row: Day 1 of lever reversal (REV DAY 1); Bottom row: fully trained (FT) to the new task. For each of these stages of reversal, behavioural performance (left), average amperometric response (middle) and AUC and Peak values (right) have been presented. Behavioural data depicts the total number of trials, rewarded lever presses (lever + ), non-rewarded lever presses (lever - ) and omissions for both cue presentations ( $\mathrm{S} 1+$ and $\mathrm{S} 2-$ ). \#\# $<0.01$ compared to ACQ day performance; ${ }^{* *} \mathrm{p}<0.01$ compared to $\mathrm{S} 1+$. Averaged $\mathrm{O}_{2}$ responses and corresponding AUC and Peak measurements are represented for rewarded lever press $(\mathrm{L}+)$ and non-rewarded lever presses $\left(\mathrm{L}-\right.$ ) following the rewarded cue $(\mathrm{S} 1+)$ presentations ( $\mathrm{L}+$ : black circles, black bars; $\mathrm{L}-$ open circles, stripped bars). ${ }^{*} \mathrm{p}<0.05$ compared to a rewarded lever press following S1+. 

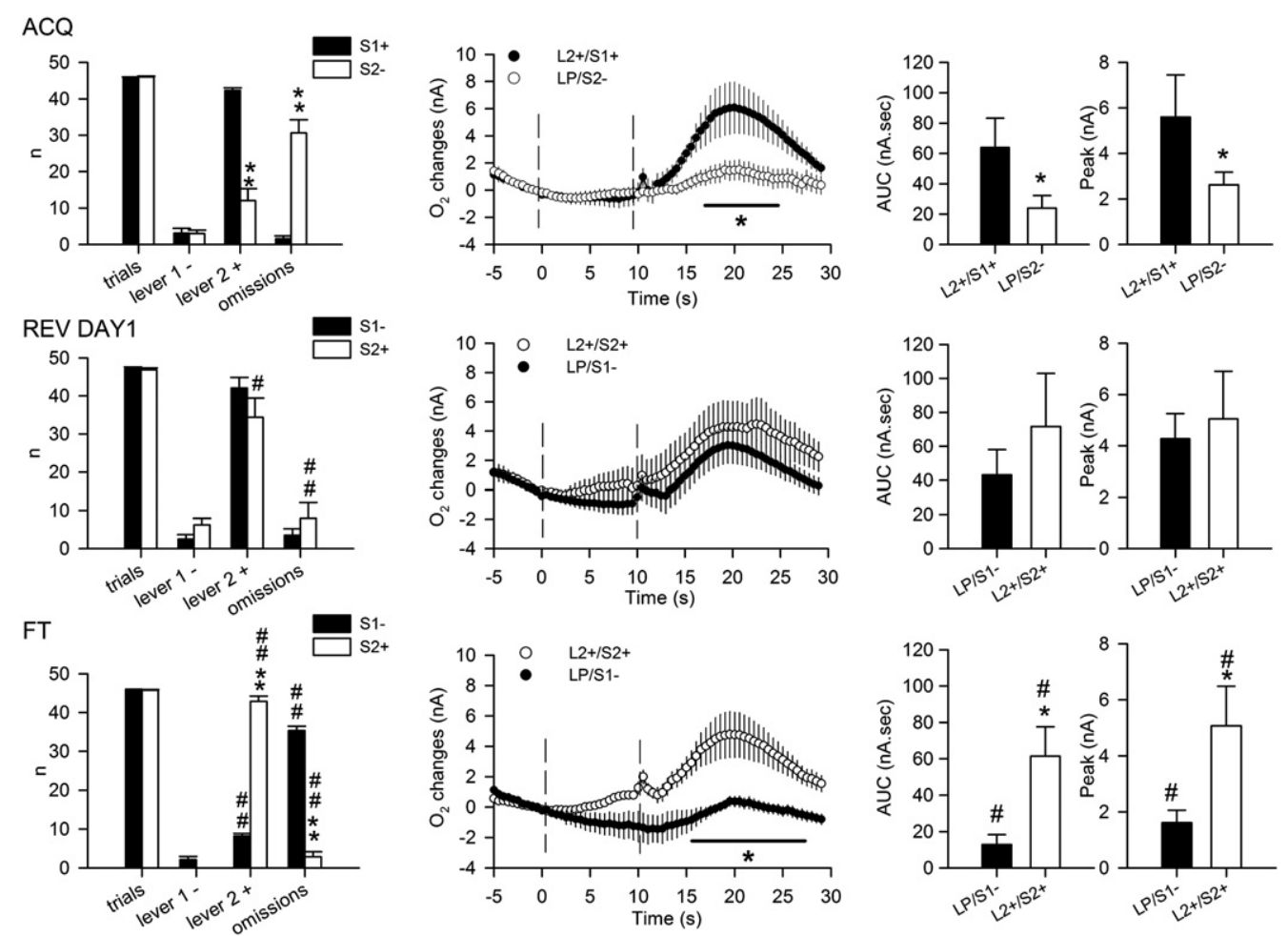

Fig. 4. Behavioural performance and $\mathrm{O}_{2}$ amperometric responses recorded in the nucleus accumbens during a cue reversal procedure (Experiment 1 ). All results are presented as mean \pm standard error of the mean. Top row: Acquired (ACQ) task performance; Middle row: Day 1 of cue reversal (REV DAY 1); Bottom row: fully trained (FT) to the new task. For each of these stages of reversal, behavioural performance (left), average amperometric response (middle) and AUC and Peak values (right) have been presented. Behavioural data depicts the total number of trials, rewarded lever presses (lever +), non-rewarded lever presses (lever-) and omissions for both cue presentations (S1 and S2) \#\#p<0.01 compared to ACQ day performance; ** $<0.01$ compared to $\mathrm{S} 1$. Averaged $\mathrm{O}_{2}$ responses and corresponding AUC and Peak measurements are represented for lever presses following each cue (S1: black circles, black bars; S2: open circles, white bars).

an asymptote (Fig. 4 REV DAY 1 row). Cue reversal also had an immediate effect on averaged $\mathrm{O}_{2}$ amperometric responses, where a significant increase in $\mathrm{NAc}_{2}$ signal was observed for both an $\mathrm{S} 2$ lever press following an $\mathrm{S} 2+$ cue and for any lever press following $\mathrm{S} 1-$ (Fig. 4, REV DAY 1 row). Thus, both cues elicited an $\mathrm{O}_{2}$ signal on the first day of cue reversal, compared to the clear dissociation in signal between $\mathrm{S}+$ and $\mathrm{S}-$ cues before reversal. When animals had reacquired the task after cue reversal, they again pressed the active lever following S2 + to receive a reward (93.7 $\pm 2.8 \%$ accuracy) and omitted responding to $\mathrm{S} 1-(76.9 \pm 2.5 \%$ omission rate). At this point in performance a significant increase in the $\mathrm{O}_{2}$ signal was again only observed for an active lever press following the current $\mathrm{S}+$ (Fig. 4, FT row). AUC and Peak measurements confirmed this, where ANOVA (behavioural response $\times$ day) revealed a significant effect of the behavioural response (AUC: $\mathrm{F}_{3,148}=9.51, \mathrm{p}<0.001$; Peak $\mathrm{F}_{3,148}=8.86, \mathrm{p}<0.001$ ) and of the interaction (AUC: $\mathrm{F}_{6,148}=3.29$, $\mathrm{p}=0.004$; Peak $\left.\mathrm{F}_{6,148}=5.67, \mathrm{p}<0.001\right)$ ) on both measures.

Temporal evolution of $\mathrm{O}_{2}$ amperometry responses (Fig. 5)

In order to assess the stability of measures obtained with this technique, animals were exposed to one further cue and lever reversal procedure. Fig. 5 illustrates how both of these additional reversals produced the same pattern of results as those presented in $\mathrm{O}_{2}$ amperometry recordings in the NAc after lever reversal and $\mathrm{O}_{2}$ amperometry recordings in the NAc after cue reversal sections above (analyses not presented).

A comparison of $\mathrm{O}_{2}$ signals produced by active lever presses following $\mathrm{S}+$ cue presentation when animals had fully re-acquired task performance after each reversal showed that increases in the $\mathrm{O}_{2}$ signal could be observed before cue offset at "Cue Reversal 1" and "Lever Reversal 2" stages. During "Acquisition", the increase in $\mathrm{O}_{2}$ signal following $\mathrm{S}+$ cue presentations was significant only from
4 to $17 \mathrm{~s}$ after cue offset, whereas after "Cue Reversal 1" and "Lever Reversal 2" $\mathrm{O}_{2}$ signals are significantly increased $4 \mathrm{~s}$ and $3 \mathrm{~s}$ before cue offset, respectively (Fig. 5).

Experiment 2: $\mathrm{O}_{2}$ amperometry recordings in the nucleus accumbens in response to receipt of rewards of differing magnitude

\section{Histology}

Following exclusion of unstable or noisy signals, 7 animals had correct bilateral or unilateral placements in the NAc that could be recorded from during the entire study. All graphs presented in this section represent an average of the responses obtained for those 7 rats. Reconstructions of the electrode placements are shown in Fig. 1C

\section{Acquisition of reward magnitude discrimination (Fig. 6)}

Animals were trained to discriminate between two rewarded cues, one associated with low reward $\left(\mathrm{S} 1+_{\text {low }}\right)$ and one associated with high reward $\left(\mathrm{S} 2+_{{ }_{\text {high }}}\right)$. A third cue never associated with reward was used as a control ( $33-$ ). After task acquisition, animals responded correctly to $S 1+{ }_{\text {low }}$ cues $(87.1 \pm 2.2 \%$ accuracy) and to $\mathrm{S} 2+{ }_{\text {high }}$ cues $(94.36 \pm 1.44 \%$ accuracy), consistent with accurate discrimination of these stimuli (Fig. 6A). No preference for either of the active levers was found following presentation of $\mathrm{S} 3-$. Analysis of the time-binned tissue $\mathrm{O}_{2}$ data (repeated measures ANOVA) revealed a significant interaction between behavioural response and time $\left(\mathrm{F}_{138,1104}=2.01, \mathrm{p}<0.001\right)$. This resulted from an increase in $\mathrm{O}_{2}$ signal only after the high rewarded active lever press following $\mathrm{S} 2+_{\text {high }}$ cues, while no similar increase could be observed for a low rewarded active lever press following $\mathrm{S} 1+_{\text {low }}$ cues or any lever press following S3 - cues (Fig. 6B). Moreover, regardless of whether AUC $\left(\mathrm{F}_{2,23}=6.22, \mathrm{p}=0.007\right)$ or Peak $\left(\mathrm{F}_{2,21}=3.6, \mathrm{p}=0.01\right)$ measurements were used, a significant increase in the $\mathrm{O}_{2}$ signal was observed 

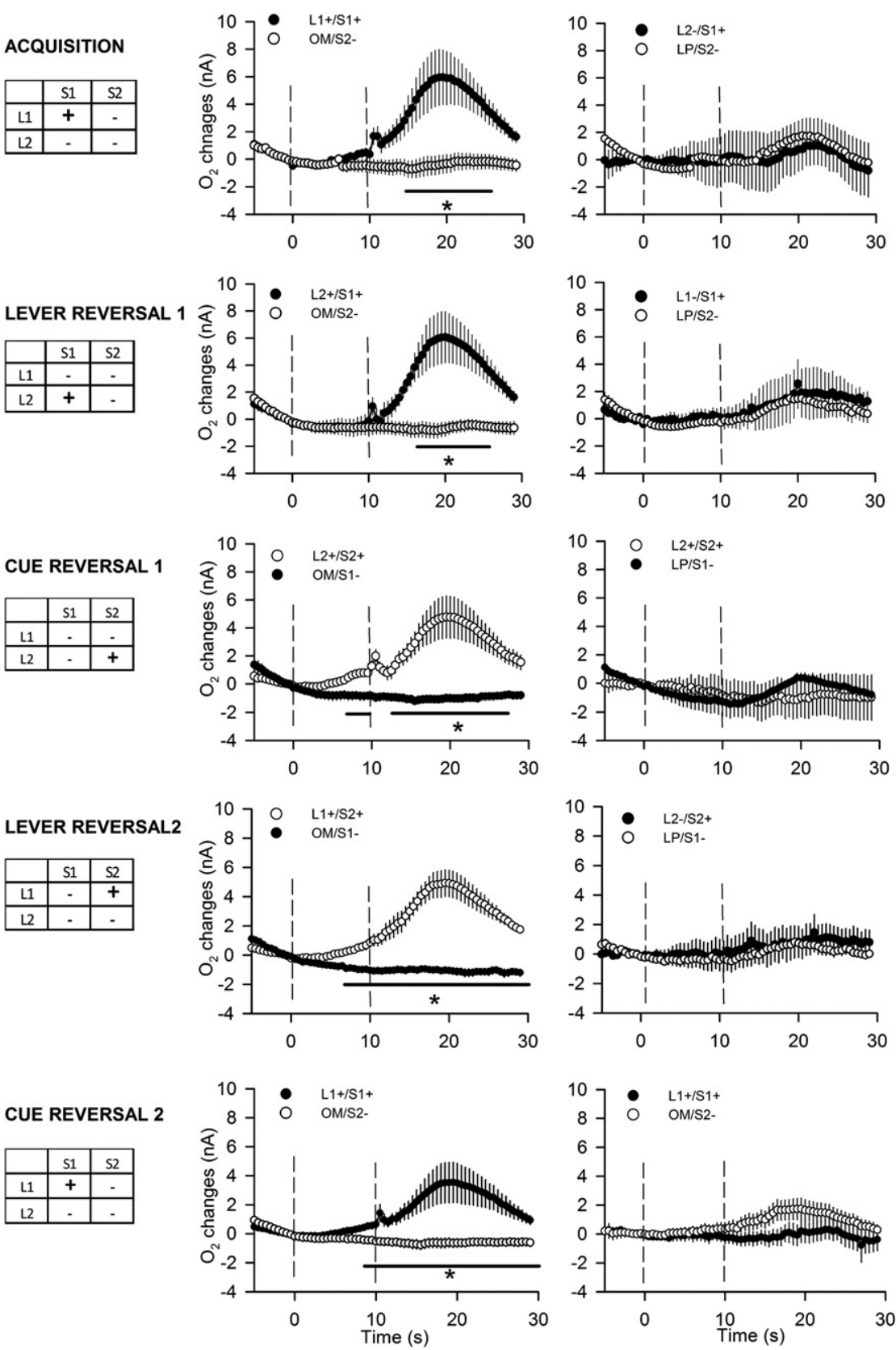

Fig. 5. Evolution of the oxygen amperometric responses with time (Experiment 1 ). All results are presented as mean \pm standard error of the mean.For each step of the experiment, a summary table of the combination of rewarded lever and cue is represented as well as the corresponding average amperometric responses measured when animals had achieved performance of the task after initial acquisition and each lever and cue reversal. S1 (black circles) and S2 (open circles) "correct" responses, i.e. a rewarded lever press ( $\mathrm{L}+/ \mathrm{S}+$ ) and an omission respectively $(\mathrm{OM} / \mathrm{S}-$ ), are presented on the left graph. S1 (black circles) and S2 (open circles) "incorrect" responses, i.e. a non-rewarded lever press ( $\mathrm{L}-/ \mathrm{S}+$ ) and a lever press respectively ( $\mathrm{LP} / \mathrm{S}-$ ) are presented on the right graph. " $\mathrm{p}<0.05$ compared to $\mathrm{S}+$ cue "correct" response.

only for the $\mathrm{S} 2+_{\text {high }}$ cue (Fig. 6C) thereby confirming the pattern previously observed.

Effect of prefeeding on reward magnitude discrimination (Fig. 7)

When animals were pre-fed to satiety by allowing ad libitum access to food during the dark phase period before testing commenced, the number of lever presses made decreased regardless of cue type (main Effect of Day: $F_{1,36}=4.75, p=0.03$, behavioural response $\times$ day, ns, Fig. 7). Compared to baseline performance on the previous day, the total number of lever presses was significantly decreased and omissions increased after prefeeding (Fig. 7B). No significant difference in $\mathrm{O}_{2}$ signals were found between $\mathrm{S} 1+_{\text {low }}$ and $\mathrm{S} 2+_{\text {high }}$ cues after prefeeding (Fig. 7C), effectively due to a loss of the increase in $\mathrm{O}_{2}$ signal previously observed following $\mathrm{S} 2+_{\text {high }}$ cues. AUC measure analyses revealed a significant effect of day $\left(F_{(1,46)}=4.19, p=0.04\right)$ and a tendency to an effect of the interaction $\left(\mathrm{F}_{(6,146)}=1.93\right.$, $\mathrm{p}=0.07$ ). Peak measures showed no significant effect of day $\left(F_{1,46}=0.77, p=0.38\right)$ and a tendency to an effect of the interaction $\left(F_{2,46}=3.08, p=0.05\right)$ Post-hoc analyses showed that these effects originated from significant decreases in both AUC and Peak measures associated with the $\mathrm{O}_{2}$ signal for $\mathrm{S} 2+_{\text {high }}$ after prefeeding (Fig. 7D).

Cue reversal during reward magnitude discrimination (Fig. 8)

A final cue reversal was conducted where reward magnitude contingencies were reversed, such that $\mathrm{S} 1$ now became the high rewarded cue $\left(\mathrm{S} 1+_{\text {high }}\right)$ and $\mathrm{S} 2$ became the low rewarded cue $\left(\mathrm{S} 2+_{\text {low }}\right)$. All other contingencies remained constant. $\mathrm{O}_{2}$ amperometric responses were analysed on selected days: REV DAY 1, the first day of reversal; REV 
A

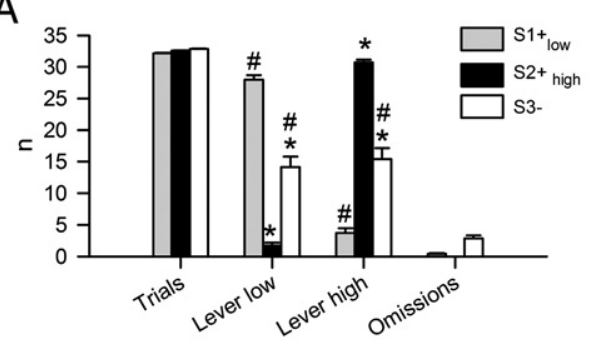

B
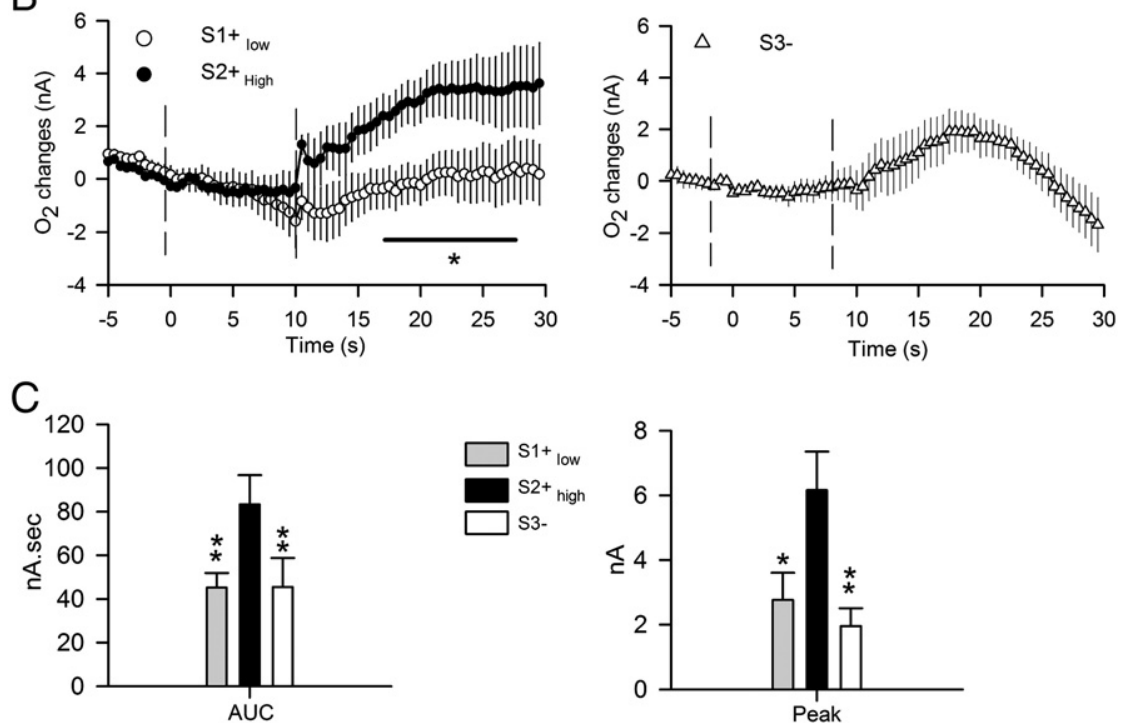

Fig. 6. Behavioural performance (A) and $\mathrm{O}_{2}$ amperometric signal recorded in the nucleus accumbens (B, C) after the acquisition of a high-low rewarded cue task (Experiment 2). All results are presented as mean \pm standard error of the mean.(A) The total number of trials, the number of lever press on the lever associated with a low reward (lever low) and the lever associated with a high reward (lever high) and the number of omissions are presented for the low rewarded cue ( $\mathrm{S} 1+_{\text {low }}$, grey bars), the high rewarded cue (S2+ ${ }_{\text {high, }}$, black bars) and the non-rewarded cue ( $\mathrm{S} 3-$, white bars). ${ }^{*} \mathrm{p}<0.01$ compared to $\mathrm{S} 1+{ }_{\text {low }}, \mathrm{\# p}<0.01$ compared to $\mathrm{S} 2+$ high. (B) The average $\mathrm{O}_{2}$ amperometric responses are presented in two different graphs. The left graph represents the rewarded responses, i.e. a correct lever press following the low rewarded cue $\left(\mathrm{S} 1+{ }_{\text {low, }}\right.$ open circle) and the high rewarded cue $\left(\mathrm{S} 2+{ }_{\text {high }}\right.$ black circle). The right graph represents the $\mathrm{O}_{2}$ responses obtained following a lever press after the non-rewarded cue (S3-, white circle). The dashed lines represent the beginning and the end of the cue presentation. * $\mathrm{p}<0.05$ compared to the oxygen signal obtained for a correct response to the low rewarded cue. The Area Under the Curve (AUC, left histogram) and Peak (right histogram) extracted from the oxygen responses are presented for the low rewarded cue $\left(\mathrm{S} 1+_{\text {low, }}\right.$ grey bars), the high rewarded cue (S2+ $+_{\text {high, }}$ black bars) and the nonrewarded cue ( $33-$, white bars). ${ }^{*} \mathrm{p}<0.05 ;{ }^{* *} \mathrm{p}<0.01$ compared to the high rewarded cue.

DAY 4, when the group displayed high levels of correct responding to $\mathrm{S} 1+_{\text {high }}$ cues; and finally when animals had fully re-acquired the task and displayed high levels of correct responding to both $\mathrm{S} 2+_{\text {low }}$ and $\mathrm{S} 1+{ }_{\text {high }}$ cues. Cue reversal had an immediate effect on behaviour related to both S1 and S2 cues. Compared to the acquisition stage, a significant decrease was observed in the number of lever presses following $\mathrm{S} 2+_{\text {low }}$ and $\mathrm{S} 1+_{\text {high }}$ presentations on the first day after cue reversal (Fig. 8, left column). Re-acquisition progressed at significantly different rates for high and low rewarded stimuli. Animals achieved a stable level of correct responding for $\mathrm{S} 1+_{\text {high }}$ after five days of reversal training, while taking 15 days to achieve a similar level of correct response for $\mathrm{S} 2+_{\text {low }}$ (Fig. 9). Statistical analysis (repeated measure ANOVAreward magnitude $\times$ day) revealed an effect of behavioural outcome $\left(\mathrm{F}_{1,12}=25.35, \mathrm{p}<0.001\right)$ and day $\left(\mathrm{F}_{16,192}=8.97, \mathrm{p}<0.001\right)$, but no behavioural outcome $\times$ day interaction. Further analysis found that accuracy to $\mathrm{S} 1+_{\text {high }}$ was greater than that for $\mathrm{S} 2+_{\text {low }}$ from days 3 to 13 (except on days 8 and 11) of re-acquisition. Analysis of time-binned tissue $\mathrm{O}_{2}$ data (repeated measure ANOVA - reward magnitude $\times$ day $\times$ time) revealed a significant interaction between reward magnitude, day and time $\left(\mathrm{F}_{69,828}=2.03, \mathrm{p}<0.001\right)$. This effect originated from a change in the relationship of the $\mathrm{O}_{2}$ signals corresponding to high and low rewarded cues from the day before cue reversal to the final day after cue reversal (day 15) and was similarly reflected in AUC and Peak measurements (Fig. 8C). Thus, prior to reversal a significant increase in $\mathrm{NAc}_{2}$ signal was observed for correct $\mathrm{S} 2+_{\text {high }}$ responses compared to correct $\mathrm{S} 1+_{\text {low }}$ responses. At the point when performance to both the reversed low and high rewarded cues $\left(\mathrm{S} 1+_{\text {high }}\right.$ and $\left.\mathrm{S} 2+_{\text {low }}\right)$ was fully re-established after cue reversal, the $\mathrm{O}_{2}$ signal was only found to significantly increase to $\mathrm{S} 1+_{\text {high }}$ cues compared to the new $\mathrm{S} 2+_{\text {low }}$ cues (Fig. 8, FT row). Thus, the relationship of $\mathrm{O}_{2}$ signals to the new high and low rewarded cues again mirrored the relationship observed at the first acquisition stage. At an intermediate stage in the re-acquisition period (REV DAY 4) no significant difference could be observed between $\mathrm{O}_{2}$ signals related to $\mathrm{S} 2+_{\text {low }}$ and $\mathrm{S} 1+_{\text {high }}$ cues (Fig. 8).

\section{Discussion}

\section{Summary of results}

In Experiment 1, after acquisition of a cued-lever pressing task a robust increase in $\mathrm{NAc}_{2}$ tissue levels was observed following a correct lever press subsequent to a rewarded cue. This $\mathrm{O}_{2}$ signal was modulated by cue reversal but not lever reversal, consistent with the $\mathrm{O}_{2}$ signal at least partly reflecting reward anticipation. In Experiment 2, changing reward magnitudes also modulated NAc activation whereby increases in the $\mathrm{O}_{2}$ signal were observed following high but not low rewarded cues. $\mathrm{NAc} \mathrm{O}_{2}$ responses to high rewarded cues were abolished by prefeeding to satiety. Finally, daily recordings in Experiment 2 during task re-acquisition after cue reversal showed 
A

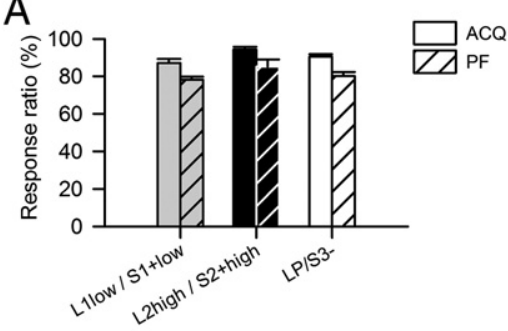

C
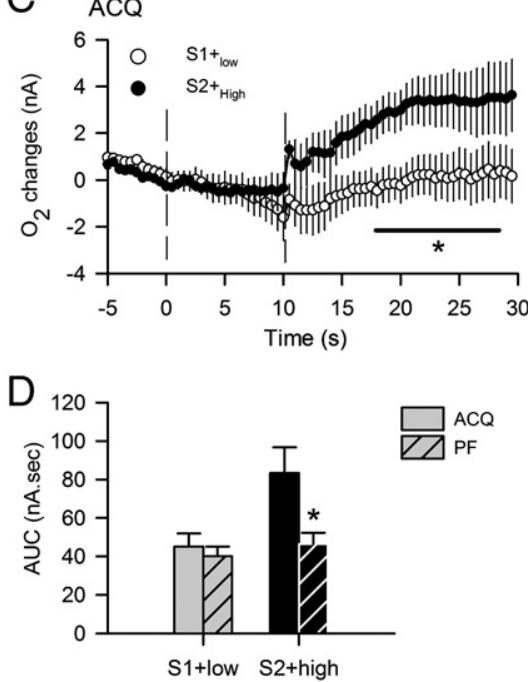

B
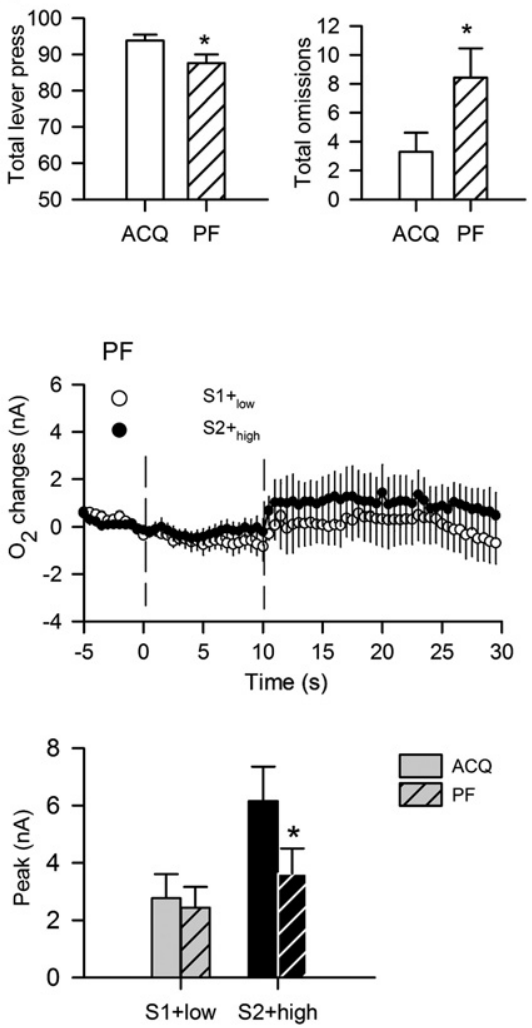

Fig. 7. Effect of prefeeding on behavioural performance (A, B) and $\mathrm{O}_{2}$ amperometric responses recorded in the nucleus accumbens (C, D) in the high-low rewarded cue task (Experiment 2). All results are presented as mean \pm standard error of the mean. (A) Graph representing the response ratio for both rewarded cues $\left(S 1+{ }_{\text {low }}\right.$ and $\left.S 2+{ }_{\text {high }}\right)$ the nonrewarded cue $(\mathrm{S} 3-$ ), before (ACQ plain bars) and after a prefeeding procedure (PF, stripped bars) * $\mathrm{p}<0.05$ compared to the values obtained before the prefeeding procedure. (B) Graphs representing the total number of lever press and the total number of omissions (all cues collapsed) over a session before (ACQ plain bars) and after a prefeeding procedure (PF, striped bars). ${ }^{*} \mathrm{p}<0.05$ compared to the values obtained before the prefeeding procedure. (C) Average $\mathrm{O}_{2}$ amperometric responses obtained following a correct lever press following the low-reward ( $\mathrm{S} 1+_{\text {low }}$, open circles) and high reward cues ( $\mathrm{S} 2+_{\text {high, }}$, black circles) before the prefeeding procedure (ACQ, left graph) and after a prefeeding procedure (PF, left graph). The dashed lines represent the beginning and the end of the cue presentation *: $p<0.05$ compared to the oxygen signal obtained for high rewarded cue. (D) Area under the curve (AUC, left histogram) and Peak (right histogram) extracted from the oxygen responses obtained before (plain bars) and after prefeeding (stripped bars) for the low rewarded $\left(\mathrm{S} 1+_{\text {low }}\right.$, grey bars) and the high rewarded cue $\left(\mathrm{S} 2_{\text {high }}\right.$, black bars). ${ }^{*} \mathrm{p}<0.05$ compared to the values obtained before the prefeeding procedure.

a similar close relationship between $\mathrm{O}_{2}$ signal and behavioural response as seen in Experiment 1.

\section{Methodological considerations}

Tissue $\mathrm{O}_{2}$ measurements have previously been more commonly conducted with Clark-type noble metal electrodes (e.g. Offenhauser et al., 2005). However, carbon-based electrodes are not prone to surface poisoning and thus do not require the use of a protecting membrane, therefore allowing a chronic recording more appropriate for behavioural neuroscience applications (Bolger et al., 2011). Secondly, in vitro experiments show no evidence of electrochemical interference in the $\mathrm{O}_{2}$ signal in the presence of physiological concentrations of potential in vivo contaminants such as dopamine, dopamine metabolites and ascorbic acid (Bolger et al., 2011). Thirdly, the study of the temporal evolution of behaviour-oxygen response coupling in Experiment 2 (Fig. 5) showed that stable $\mathrm{O}_{2}$ responses could be observed over a period of several months, in concordance with previous studies (Bolger et al., 2011; Fillenz and O'Neill, 1986). Finally, while the relatively large size of CPEs may cause tissue damage that could influence the signal measured (Duff and O'Neill, 1994), as described for similarly sized microdialysis probes on dopamine measurements (Khan and Michael, 2003), there is no evidence to suggest that this also occurs when CPEs are used to measure a freely diffusing gaseous species such as $\mathrm{O}_{2}$ (Bolger et al., 2011). Also, the current studies employed a long healing time ( 2 weeks) to allow brain tissue to recover following electrode implantation. Constant potential amperometry at carbon paste electrodes therefore offers a continuous real-time $\mathrm{O}_{2}$ recording technique with high sensitivity, low interference, rapid response time and long-term stability in vivo making it highly suitable for use in behaving animals.

\section{Temporal dynamics of the amperometric signal}

The most prominent aspect of the NAc amperometric $\mathrm{O}_{2}$ signal presented with a characteristic shape and temporal profile, being a smooth rise to peak occurring $19.4 \pm 1.4 \mathrm{~s}$ after cue onset $(9.4 \pm$ $0.7 \mathrm{~s}$ after cue offset) and declining to baseline with a comparable shape. In studies of accumbens responding during monetary incentive delay tasks, the human NAC BOLD signal appears to have a similar shape to that of the rodent amperometric signal, but the peak occurs approximately $7 \mathrm{~s}$ after cue presentation (Knutson et al., 2001). In this light, the peak amperometric $\mathrm{O}_{2}$ response seems somewhat slower than the peak human BOLD response relative to the onset of a cue that predicts reward. However, relative to cue offset, which may be a more salient event for animals in the present study, the temporal profiles are more similar. This will be examined in future studies by systematically varying both stimulus length and the interval between cue offset and reward delivery with the prediction that the timing to peak oxygen response will remain relatively constant regardless of stimulus length or the interval between cue offset and reward delivery (within the limits of the generation of frustrative non-reward). It is notable that in contrast to the instrumental response and transit to food magazine in rats, the reward of monetary gain in humans is 
ACQ
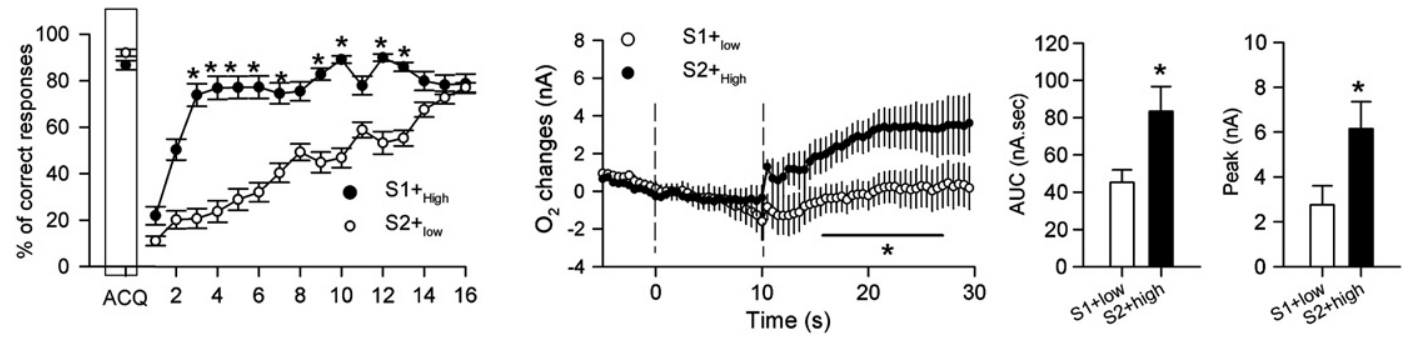

\section{REV DAY1}
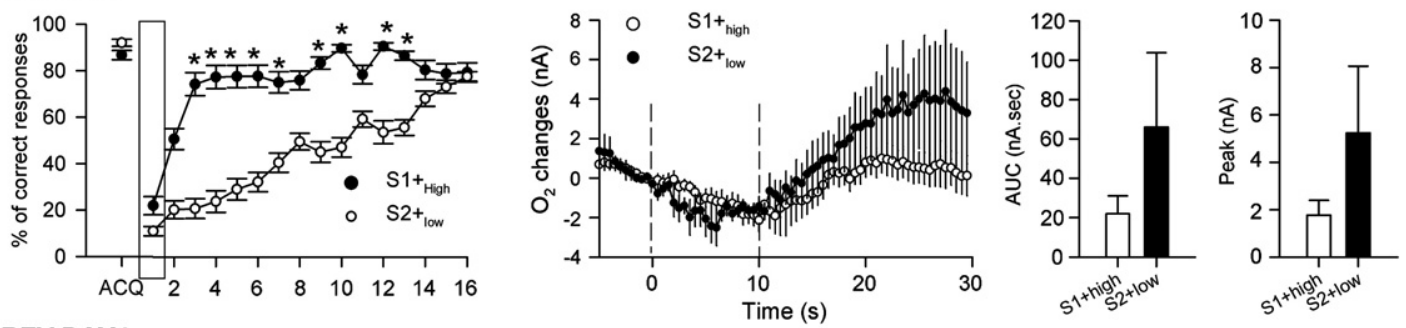

\section{REV DAY4}
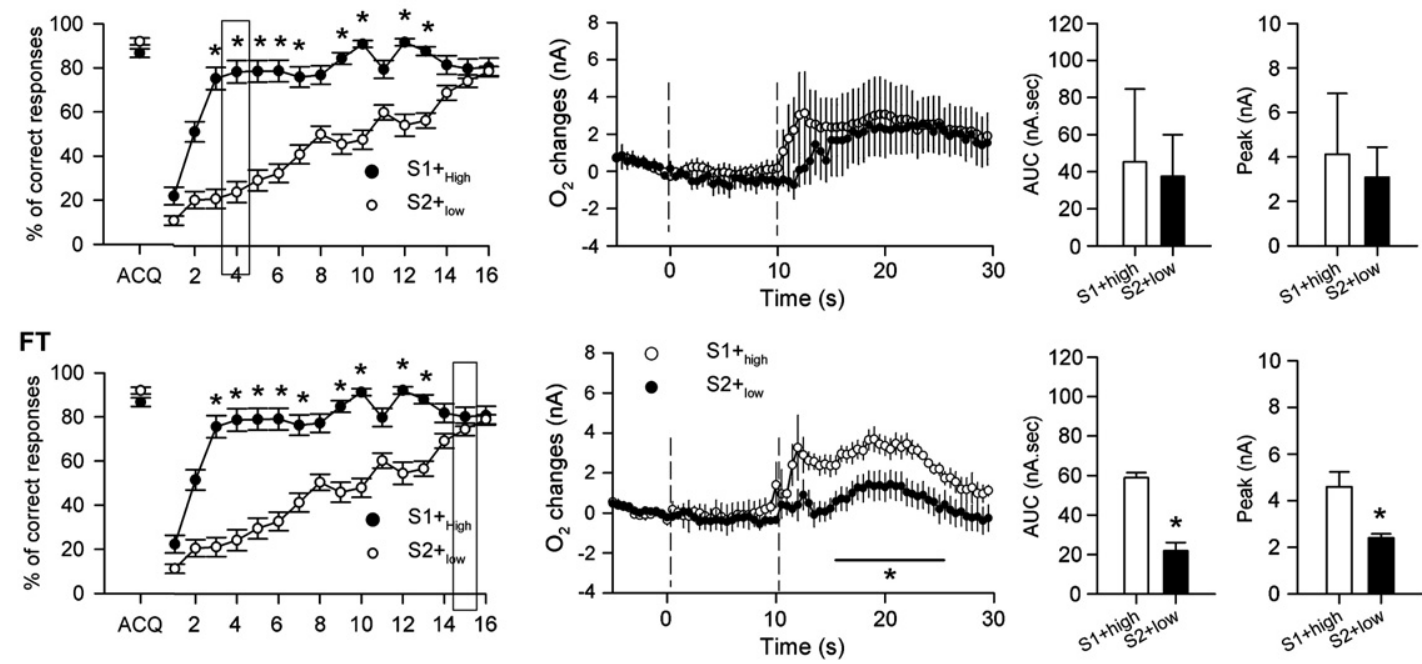

Fig. 8. Behavioural performance and $\mathrm{O}_{2}$ amperometric responses recorded in the nucleus accumbens during a rewarded-cue reversal procedure (Experiment 2 ). All results are presented as mean \pm standard error of the mean. The behavioural performance and average $\mathrm{O}_{2}$ amperometric responses are presented for several steps of the cue reversal procedure: Before the cues were reversed (ACQ), the first and the fourth day after the reversal (REV DAY1 and REV DAY 4) and when the animals are fully trained (FT). For each step, the percentage of correct responses (left graph) for the low rewarded $\left(\mathrm{S}+_{\text {low }}\right)$ and the high rewarded $\left(\mathrm{S}+{ }_{\text {high }}\right)$ cues are represented over the whole reversal process. ${ }^{*} \mathrm{p}<0.05$ compared to the values obtained for the low rewarded cue. The black box represents the day where the $\mathrm{O}_{2}$ amperometric responses were analyzed (middle graph). The right graphs represent the area under the curve (AUC) and the peak values extracted from the corresponding $\mathrm{O}_{2}$ amperometric responses. * $\mathrm{p}<0.05$ compared to the values obtained before the high rewarded cue.

symbolic and careful analysis of these factors will be needed to gain deeper insight into the equivalence of signals here. Interestingly, both the human BOLD signal and the rat amperometric $\mathrm{O}_{2}$ signal peaks are considerably slower than measurements of VTA and NAC neuronal activity (e.g. Ambroggi et al., 2011), and release of dopamine in the accumbens as measured by fast-scan voltammetry (e.g. Day et al., 2007). These differences in timing of activities make it plausible that the amperometric signal could be driven by a haemodynamic response subsequent to these bursts in synaptic and local field activity.

Whilst AUC and peak measures of the $\mathrm{O}_{2}$ amperometric signal describe a response that is comparable in timescale to the human NAc BOLD response under similar circumstances, it is worth noting that there might be other aspects of the amperometric signal that occur at faster timescales. Firstly, as described in Temporal evolution of $\mathrm{O}_{2}$ amperometry responses section, the latency of the initial rise in the $\mathrm{O}_{2}$ signal decreased with progressive sessions of testing, such that eventually a significant increase in $\mathrm{NAc}_{2}$ occurred $4 \mathrm{~s}$ before cue offset. Secondly, a very small transient increase in the $\mathrm{O}_{2}$ response was observed on several occasions (e.g. Figs. 2, 4, 5) occurring within $1 \mathrm{~s}$ of cue offset. This was rarely seen in animals that made an incorrect response that was not rewarded. It is tempting to speculate that this might be a biologically relevant signal related to receipt of the food reward, but the contribution of a mechanical artefact to this transient cannot be completely ruled out at present.

\section{Nucleus accumbens activation and reward anticipation}

One of the most striking and consistent results obtained in this study was the specific increase in NAc tissue $\mathrm{O}_{2}$ levels in response to rewarded lever presses following presentation of a rewarded cue. Three different behavioural components could be related to, and potentially driving, this increase, 1 ) the lever press itself, 2) the delivery of reward or 3) the incentive/motivational value of the cues that predict reward. With regard to the first point, the fact that lever presses following non-rewarded cues did not induce $\mathrm{O}_{2}$ signals suggests that operant responses per se are not the principal component driving the increase. Moreover, $\mathrm{NAc}_{2}$ signals remained unchanged by a lever 
reversal procedure but were strongly modulated by a cue reversal procedure, suggesting sensitivity to changes in incentive salience states of stimuli rather than changes in effective instrumental outputs. Finally, on the first day after a cue reversal, lever presses for the now non-rewarded cue still induced increases in $\mathrm{NAc}_{2}$ signals, an effect that likely reflected the continued expectation of the reward previously associated with the cue. Comparison of the first 5 presentations of the $\mathrm{S}+$ cue during the last day of acquisition with the first 5 presentations of the $S$ - cue on the first day after cue reversal did not indicate any significant difference in $\mathrm{O}_{2}$ responses obtained (Supplementary Fig. S1). As S- cues are not rewarded, the signal obtained for those responses cannot be driven by the reward itself, making a reward expectation account a plausible alternative. Our findings are consistent with several human neuroimaging studies showing an activation of the NAc during the anticipatory phase of a monetary incentive delay task (Ernst et al., 2004; Kirsch et al., 2003; Knutson et al., 2000). A straightforward acceptance of the reward anticipation account is somewhat challenged by the lack of significant increase in $\mathrm{NAc} \mathrm{O}_{2}$ signal following incorrect lever choice to the $\mathrm{S}+$. However, other electrophysiological studies in animals performing a similar task have shown that NAc neuronal responses to the S+ are significantly greater when rats make correct rather than incorrect operant responses to the cue, in accordance with the smaller increases observed in our study (Nicola et al., 2004).

Altogether the results are consistent with a role for NAc in signalling reward expectation, rather than an instrumental (motor) output or the receipt of reward itself. Reward expectation can plausibly be driven by two different psychological processes, either via response to the hedonic value of reward ("liking") or via response to the motivational incentive value of reward ("wanting") (Pecina, 2008). The two processes of "liking" and "wanting" remain hard to disambiguate as it is reasonable to suggest that an expected reward could be "liked" as much as a delivered one. Some of the data presented in this study may help to address this issue. For example, in Experiment 2, animals were trained to discriminate between two cues associated with two reward magnitudes. On the first day after a reversal of cue contingencies, an increase in the $\mathrm{O}_{2}$ signal was observed only following the cue that was now associated with a small reward and no increase was observed for the cue now associated with the high reward. If the $\mathrm{O}_{2}$ signal increase was only linked to the immediate hedonic value of the reward predicted by the cue, it might have been expected that an increase in $\mathrm{NAc}_{2}$ signal would be observed following high reward delivery whatever cue was presented. However, the actual $\mathrm{O}_{2}$ signal increase was unchanged compared to the day before cue reversal suggesting that NAC is activating in response to the motivational incentive value of the cue, i.e. the NAc signal reflects how the animal "wants" the reward that has been associated with that cue.

\section{Nucleus accumbens activation and reward magnitude coding}

In order to use a cue to optimally guide reward-directed behaviour, NAc activation might carry information about the probability of an instrumental action to lead to a positive outcome, the magnitude of this outcome, and the motivational state of the animal with regard to achieving this outcome. In this study, the potential for probabilistic coding in the NAc could not be assessed as reward delivery was always set at a probability of 1 or 0 . Results from Experiment 2 tended to confirm the second point: that NAc activation might contain a representation of reward magnitude. In the biconditional task variant where animals discriminated between two cues associated with two different reward magnitudes, NAc $\mathrm{O}_{2}$ signal increases were only observed for the cue that predicted the highest reward. Similarly, Roesch et al. (2009) utilized a choice task in the rat in which reward magnitude was manipulated and found that NAc neurons displayed greater increases in firing immediately prior to selection of higher value options. Other studies of electrophysiology and dopamine release in rats have also shown that both neuronal firing or dopamine release tend to signal the "better" of two reward options rather than their absolute value (Day et al., 2010; Roesch et al., 2007). Studies in monkeys have also tried to address whether striatal activations incorporate details of upcoming rewards and have demonstrated differences in activation patterns induced by two different types of juices (Hassani et al., 2001) as well as rewards of different magnitudes (Cromwell and Schultz, 2003). Finally, human neuroimaging studies have shown a specific relationship between BOLD signal increase in the NAc and magnitude of reward (Cooper and Knutson, 2008; Knutson and Cooper, 2005; Yacubian et al., 2006) and dichotomous activation for the cue predicting the greatest available reward value has also been observed (Ballard and Knutson, 2009). As a whole these data clearly suggest that NAc neuronal activity is modulated as a function of expected reward magnitude, which likely explains the changes in $\mathrm{O}_{2}$ signal observed in our study.

Another psychological process that could be encoded in the anticipatory signal observed in the NAc is the internal motivational state of animals. Expecting a larger reward might have induced a greater increase in $\mathrm{NAc}_{2}$ which could be explained by a reward magnitude coding account as described previously, but alternatively by the fact that the animal might have been more motivated to obtain larger rewards. Prefeeding animals to satiety led to a global decrease in the number of lever presses made regardless of cue presentation, consistent with a global decrease in the motivation of animals to perform the task. This decrease in motivation was also associated with a lack of activation of the NAc following cues predicting delivery of high reward even though reward value per se remained unchanged. Thus, these results are consistent with the possibility that the NAc could play a role in coding the motivational state of animals. Similar results have been obtained in human neuroimaging studies which have shown increasing NAc activation with increasing self-reported positive arousal (Cooper and Knutson, 2008; Drevets et al., 2001; Knutson and Cooper, 2005). Neuroimaging, electrophysiological and the present $\mathrm{O}_{2}$ amperometric data suggest that the NAc is involved in a broad coding of different aspects of reward processing including constructs of anticipation, reward magnitude and motivational state.

\section{Physiological origin of the $\mathrm{O}_{2}$ signal}

Dopamine neurons in the midbrain are known to encode stimulus-reward associations and a recent hypothesis suggests that NAC activation could provide a prediction error signal capable of representing a mismatch between actual and predicted events in a manner that can guide associative learning processes (Schultz and Dickinson, 2000). The increase in $\mathrm{O}_{2}$ signal observed while animals are performing in the present study could therefore be related to activity of mesolimbic dopamine neurons, which represent a major afferent input of the NAc. Electrophysiological studies have shown that dopaminergic neurons fire not only in response to unexpected reward but also to cues that predict delivery of reward (Schultz et al., 1997). Moreover, Roitman et al. (2004) showed that reward-predicting cues cause midbrain dopamine projections to release dopamine in regions of the ventral striatum, including the NAc. Similarly, dopamine measurements in the NAc using fast-scan cyclic voltammetry have shown a greater amount of dopamine delivered following an S+ compared to an S- cue after Pavlovian conditioning (Day et al., 2007; Stuber et al., 2008). Finally, neuronal firing in the NAc has been shown to commence rapidly after cue onset and to be greater for S+ than Scues (Hassani et al., 2001; Nicola et al., 2004). Thus, release of dopamine in the NAc from VTA afferents and nucleus accumbens neuronal activity are both clearly implicated in encoding the predictive value of rewarding cues.

The signal measured by CPA represents extracellular tissue concentrations of $\mathrm{O}_{2}$ and is therefore a dynamic balance between consumption and supply (Lowry et al., 1997). Recordings in this study 
were conducted in conscious behaving animals with changes in $\mathrm{O}_{2}$ signals observed occurring over a period of seconds and thus more likely to reflect supply rather than consumption. As such, the $\mathrm{O}_{2}$ signals are likely to be highly dependent on cerebral blood flow (CBF), in a manner similar to the BOLD signal measured in fMRI studies. The relationship between neuronal activity and haemodynamic response is still a question under considerable debate (Attwell and Iadecola, 2002; Lauritzen, 2005; Logothetis et al., 2001). However, several studies have shown that increases in local CBF are mainly driven by afferent input to regions of interest (Logothetis et al., 2001; Mathiesen et al., 1998 ) and are therefore best correlated to local field potentials rather than spiking activity (Masamoto et al., 2008; Mathiesen et al., 1998). It is then plausible that the amperometric signal could be driven by a haemodynamic response subsequent to dopaminergic terminal release and changes in local field activity in the NAc induced by midbrain dopamine neurons. Several studies assessing the link between dopaminergic neurotransmission and BOLD responses argue in favour of this. Indeed, simultaneous measures of dopamine, blood flow and $\mathrm{O}_{2}$ in rats have shown that terminal activity induced by stimulation of the VTA dopaminergic neurons increases blood flow in the caudate/putamen and caused an increase in local $\mathrm{O}_{2}$ (Venton et al., 2003). Moreover, phMRI studies have shown that dopamine releasing agents or agents that block dopamine reuptake increase the BOLD signal in NAc (for review, Knutson and Gibbs, 2007) and that unilateral lesions of dopamine neurons in rat striatum abolished this effect (Chen et al., 1997; Chen et al., 1999; Knutson and Gibbs, 2007). Similarly, a neuroimaging study combining $\left[{ }^{11} \mathrm{C}\right]$ raclopride positron emission tomography and fMRI showed a strong correlation between BOLD activation during reward anticipation and reward-related dopamine release in the ventral striatum in humans performing a monetary incentive delay task (Schott et al., 2008). Further confirmation of the role of dopaminergic activity in the generation of amperometric $\mathrm{O}_{2}$ responses in the NAc can be obtained with studies involving coupling of $\mathrm{O}_{2}$ amperometric responding with pharmacological and/or electrophysiological manipulations.

\section{Conclusion}

In vivo $\mathrm{O}_{2}$ amperometric recordings have demonstrated that, as in human fMRI studies, the NAc is activated during anticipation of reward. Furthermore, this activation can be modulated by varying the magnitude and/or motivational incentive value of the reward. The close relationship between behavioural and $\mathrm{O}_{2}$ amperometric responses and similarities observed between our results and human fMRI studies using the monetary incentive delay task suggest that $\mathrm{O}_{2}$ amperometry can be used as a valid surrogate for fMRI in freely moving rodents performing tasks involving reward processing.

Supplementary materials related to this article can be found online at doi:10.1016/j.neuroimage.2012.02.024.

\section{Conflict of interest}

Jennifer Francois, Michael Conway, Gary Gilmour and Mark Tricklebank are employees of Eli Lilly \& Co Ltd.

\section{References}

Ambroggi, F., Ghazizadeh, A., Nicola, S.M., Fields, H.L., 2011. Roles of the nucleus accumbens core and shell in incentice cue responding and behavioural inhibition. J. Neurosci. 31 (18), 6820-6830.

Attwell, D., Iadecola, C., 2002. The neural basis of functional brain imaging signals. Trends Neurosci. 25, 621-625.

Ballard, K., Knutson, B., 2009. Dissociable neural representations of future reward magnitude and delay during temporal discounting. Neuroimage 45 (1), 143-150.

Bolger, F.B., McHugh, S.B., Bennett, R., Li, J., Ishiwari, K., Francois, J., Conway, M.W. Gilmour, G., Bannerman, D.M., Fillenz, M., Tricklebank, M., Lowry, J.P., 2011.
Characterisation of carbon paste electrodes for real-time amperometric monitoring of brain tissue oxygen. J. Neurosci. Methods 195, 135-142.

Chen, Y.I., Galpern, W.R., Brownell, A.L., Matthews, R.T., Bogdanov, M., Isacson, O., Keltner, J.R., Beal, M.F., Rosen, B.R., Jenkins, B.G., 1997. Detection of dopaminergic neurotransmitter activity using pharmacologic MRI: correlation with PET, microdialysis, and behavioral data. Magn. Reson. Med. 38, 389-398.

Chen, Y.I., Brownell, A.L., Galpern, W., Isacson, O., Bogdanov, M., Beal, M.F., Livni, E., Rosen, B.R., Jenkins, B.G., 1999. Detection of dopaminergic cell loss and neural transplantation using pharmacological MRI, PET and behavioral assessment. Neuroreport 10, 2881-2886.

Cooper, J.C., Knutson, B., 2008. Valence and salience contribute to nucleus accumbens activation. Neuroimage 39, 538-547.

Cromwell, H.C., Schultz, W., 2003. Effects of expectations for different reward magnitudes on neuronal activity in primate striatum. J. Neurophysiol. 89, 2823-2838.

Dahlström, A., Fuxe, K., 1964. Evidence for the existence of monoamine-containing neurons in the central nervous system. I. Demonstration of monoamines in the cell bodies of brain stem neurons. Acta Physiol. Scand. Suppl. 232, 1-55.

Day, J.J., Roitman, M.F., Wightman, R.M., Carelli, R.M., 2007. Associative learning mediates dynamic shifts in dopamine signallingin the nucleus accumbens. Nat. Neurosci. 10 (8), 1020-1028.

Day, J.J., Jones, J.L., Wightman, R.M., Carelli, R.M., 2010. Phasic nucleus accumbens dopamine release encodes effort- and delay-related costs. Biol. Psychiatry 68 (3), 306-309.

Drevets, W.C., Gautier, C., Price, J.C., Kupfer, D.J., Kinahan, P.E., Grace, A.A., Price, J.L Mathis, C.A., 2001. Amphetamine-induced dopamine release in human ventral striatum correlates with euphoria. Biol. Psychiatry 49, 81-96.

Duff, A., O'Neill, R.D., 1994. Effect of probe size on the concentration of brain extracellular uric acid monitored with carbon paste electrodes. J. Neurochem. 62 (4), 1496-1502 (Apr).

Ernst, M., Nelson, E.E., McClure, E.B., Monk, C.S., Munson, S., Eshel, N., Zarahn, E. Leibenluft, E., Zametkin, A., Towbin, K., Blair, J., Charney, D., Pine, D.S., 2004. Choice selection and reward anticipation: an fMRI study. Neuropsychologia 42, 1585-1597.

Fallon, J.H., Moore, R.Y., 1978. Catecholamine innervations of the basal forebrain. IV. Topography of the dopamine projection to the basal forebrain and neostriatum. J. Comp. Neurol. 180, 545-580.

Fields, H.L., Hjelmstad, G.O., Margolis, E.B., Nicola, S.M., 2007. Ventral tegmental area neurons in learned appetitive behaviour and positive reinforcement. Annu. Rev. Neurosci. 30, 289-316.

Fillenz, M., O'Neill, R.D., 1986. Effects of light reversal on the circadian pattern of motor activity and voltammetric signals recorded in rat forebrain. J. Physiol. 374, 91-101.

Hassani, O.K., Cromwell, H.C., Schultz, W., 2001. Influence of expectation of different rewards on behavior-related neuronal activity in the striatum. J. Neurophysiol. 85, 2477-2489.

Hitchman, M.L., 1978. Measurement of Dissolved Oxygen. John Wiley \& Sons Inc., New York, p. 103.

Justice, J.B.J., 1987. Introduction to in vivo voltammetry. In: Justice Jr., J.e. (Ed.), Voltammetry in the Neurosciences: Principles, Methods, and Applications. Humana Press, Clifton, NJ, p. 45

Khan, A.S., Michael, A.C., 2003. Invasive consequences of using micro-electrodes and microdialysis probes in the brain. Trends Anal. Chem. 22, 503-508.

Kirsch, P., Schienle, A., Stark, R., Sammer, G., Blecker, C., Walter, B., Ott, U., Burkart, J., Vaitl, D., 2003. Anticipation of reward in a nonaversive differential conditioning paradigm and the brain reward system: an event-related fMRI study. Neuroimage 20, 1086-1095.

Knutson, B., Cooper, J.C., 2005. Functional magnetic resonance imaging of reward prediction. Curr. Opin. Neurol. 18, 411-417.

Knutson, B., Gibbs, S.E., 2007. Linking nucleus accumbens dopamine and blood oxygenation. Psychopharmacology (Berl) 191, 813-822.

Knutson, B., Westdorp, A., Kaiser, E., Hommer, D., 2000. FMRI visualization of brain activity during a monetary incentive delay task. Neuroimage 12, 20-27.

Knutson, B., Adams, C.M., Fong, G.W., Hommer, D., 2001. Anticipation of increasing monetary reward selectively recruits nucleus accumbens. J. Neurosci. 21, RC159.

Lauritzen, M., 2005. Reading vascular changes in brain imaging: is dendritic calcium the key? Nat. Rev. Neurosci. 6, 77-85.

Logothetis, N.K., Pauls, J., Augath, M., Trinath, T., Oeltermann, A., 2001. Neurophysiological investigation of the basis of the fMRI signal. Nature 412, 150-157.

Lowry, J.P., Boutelle, M.G., O'Neill, R.D., Fillenz, M., 1996. Characterization of carbon paste electrodes in vitro for simultaneous amperometric measurement of changes in oxygen and ascorbic acid concentrations in vivo. Analyst 121 (6), 761-766.

Lowry, J.P., Boutelle, M.G., Fillenz, M., 1997. Measurement of brain tissue oxygen at a carbon past electrode can serve as an index of increases in regional cerebral blood flow. J. Neurosci. Methods 71, 177-182.

Lowry, J.P., Griffin, K., McHugh, S.B., Lowe, A.S., Tricklebank, M., Sibson, N.R., 2010. Realtime electrochemical monitoring of brain tissue oxygen: a surrogate for functional magnetic resonance imaging in rodents. Neuroimage 52, 549-555.

Martel, D., Kuhn, A., 2000. Electrocatalytic reduction of $\mathrm{H}_{2} \mathrm{O}_{2}$ at $\mathrm{P}_{2} \mathrm{Mo}_{18} \mathrm{O}_{62}^{6-}$ modified glassy carbon. Electrochemica Acta 49, 1829-1836.

Masamoto, K., Vazquez, A., Wang, P., Kim, S.G., 2008. Trial-by-trial relationship between neural activity, oxygen consumption, and blood flow responses. Neuroimage 40, 442-450.

Mathiesen, C., Caesar, K., Akgoren, N., Lauritzen, M., 1998. Modification of activitydependent increases of cerebral blood flow by excitatory synaptic activity and spikes in rat cerebellar cortex. J. Physiol. 512 (Pt 2), 555-566.

McHugh, S.B., Fillenz, M., Lowry, J.P., Rawlins, J.N., Bannerman, D.M., 2011. Brain tissue oxygen amperometry in behaving rats demonstrates functional dissociation of dorsal and ventral hippocampus during spatial processing and anxiety. Eur. J. Neurosci. 33, 322-337. 
Nicola, S.M., Yun, I.A., Wakabayashi, K.T., Fields, H.L., 2004. Cue-evoked firing of nucleus accumbens neurons encodes motivational significance during a discriminative stimulus task. J. Neurophysiol. 91, 1840-1865.

Nicola, S.M., Taha, S.A., Kim, S.W., Fields, H.L., 2005. Nucleus accumbens dopamine release is necessary and sufficient to promote the behavioral response to rewardpredictive cues. Neuroscience 135, 1025-1033.

O'Doherty, J.P., 2004. Reward representations and reward-related learning in the human brain: insights from neuroimaging. Curr. Opin. Neurobiol. 14, 769-776.

Offenhauser, N., Thomsen, K., Caesar, K., Lauritzen, M., 2005. Activity-induced tissue oxygenation changes in rat cerebellar cortex: interplay of postsynaptic activation and blood flow. J. Physiol. 565, 279-294.

Olds, J., Milner, P., 1954. Positive reinforcement produced by electrical stimulation of septal area and other regions of rat brain. J. Comp. Physiol. Psychol. 47, 419-427.

O'Neill, R.D., Grunewald, R.A., Fillenz, M., Albery, W.J., 1982. Linear sweep voltammetry with carbon paste electrodes in the rat striatum. Neuroscience 7, 1945-1954.

Ongur, D., Price, J.L., 2000. The organization of networks within the orbital and medial prefrontal cortex of rats, monkeys and humans. Cereb. Cortex 10, 206-219.

Paxinos, G., Watson, C., 2005. The Rat Brain in stereotaxic coordinates Fifth Edition. Academic Press/Elsevier, San Diego.

Pecina, S., 2008. Opioid reward 'liking' and 'wanting' in the nucleus accumbens. Physiol. Behav. 94, 675-680.

Roesch, M.R., Calu, D.J., Schoenbaum, G., 2007. Dopamine neurons encode the better option in rats deciding between differently delayed or sized rewards. Nat. Neurosci. 10 (12), 1615-1624 Dec.

Roesch, M.R., Singh, T., Brown, P.L., Mullins, S.E., Schoenbaum, G., 2009. Ventral striatal neurons encode the value of the chosen action in rats deciding between differently delayed or sized rewards. J. Neurosci. 29, 13365-13376.

Roitman, M.F., Stuber, G.D., Phillips, P.E., Wightman, R.M., Carelli, R.M., 2004. Dopamine operates as a subsecond modulator of food seeking. J. Neurosci. 24, 1265-1271.

Schott, B.H., Minuzzi, L., Krebs, R.M., Elmenhorst, D., Lang, M., Winz, O.H., Seidenbecher, C.I., Coenen, H.H., Heinze, H.J., Zilles, K., Düzel, E., Bauer, A., 2008. Mesolimbic functional magnetic resonance imaging activations during reward anticipation corre- late with reward-related ventral striatal dopamine release. J. Neurosci. 28 , 14311-14319.

Schultz, W., Dickinson, A., 2000. Neuronal coding of prediction errors. Annu. Rev. Neurosci. 23, 473-500

Schultz, W., Dayan, P., Montague, P.R., 1997. A neural substrate of prediction and reward. Science 275, 1593-1599.

Spreckelmeyer, K.N., Krach, S., Kohls, G., Rademacher, L., Irmak, A., Konrad, K., Kircher T., Grunder, G., 2009. Anticipation of monetary and social reward differently activates mesolimbic brain structures in men and women. Soc. Cogn. Affect. Neurosci. $4,158-165$.

Stuber, G.D., Klanker, M., de Ridder, B., Bowers, M.S., Joosten, R.N., Feenstra, M.G., Bonci, A., 2008. Reward-predictive cues enhance excitatory synaptic strength onto midbrain dopamine neurons. Science 321 (5896), 1690-1692.

Swanson, L.W., 1982. The projections of the ventral tegmental area and adjacent regions: a combined fluorescent retrograde tracer and immunofluorescence study in the rat. Brain Res. Bull. 9, 321-353.

Taylor, R.J., Humffray, A.A., 1975. Electrochemical studies on glassy carbon electrodes. 2. Oxygen reduction in solutions of high $\mathrm{Ph}$ (Ph greater-than 10). J. Electroanal. Chem. 64, 63-84.

Thompson, J.K., Peterson, M.R., Freeman, R.D., 2003. Single-neuron activity and tissue oxygenation in the cerebral cortex. Science 299, 1070-1072.

Tobler, P.N., Fiorillo, C.D., Schultz, W., 2005. Adaptive coding of reward value by dopamine neurons. Science 307, 1642-1645.

Venton, BJ. Michael, DJ., Wightman, R.M. 2003. Correlation of local changes extracellular oxygen and $\mathrm{pH}$ that accompany dopaminergic terminal activity in the rat caudate-putamen. J. Neurochem. 84 (2), 373-381 Jan.

Viswanathan, A., Freeman, R.D., 2007. Neurometabolic coupling in cerebral cortex reflects synaptic more than spiking activity. Nat. Neurosci. 10, 1308-1312.

Yacubian, J., Glascher, J., Schroeder, K., Sommer, T., Braus, D.F., Buchel, C., 2006. Dissociable systems for gain- and loss-related value predictions and errors of prediction in the human brain. J. Neurosci. 26, 9530-9537.

Zimmerman, J.B., Wightman, R.M., 1991. Simultaneous electrochemical measurements of oxygen and dopamine in vivo. Anal. Chem. 63, 24-28. 